\title{
Fibroblast growth factor receptor 4 (FGFR4) and fibroblast growth factor 19 (FGF19) autocrine enhance breast cancer cells survival
}

\author{
Kai Hung Tiong ${ }^{1,2,3}$, Boon Shing Tan ${ }^{1,4}$, Heng Lungh Choo ${ }^{1,5}$, Felicia Fei-Lei Chung ${ }^{5}$, \\ Ling-Wei Hii ${ }^{1,5}$, Si Hoey Tan ${ }^{1,5}$, Nelson Tze Woei Khor ${ }^{6}$, Shew Fung Wong7, Sze-Jia \\ See $^{5}$, Yuen-Fen Tan ${ }^{1,5}$, Rozita Rosli ${ }^{8}$, Soon-Keng Cheong ${ }^{9}$, Chee-Onn Leong ${ }^{5,10}$ \\ ${ }^{1}$ School of Postgraduate Studies, International Medical University, Bukit Jalil, Kuala Lumpur, Malaysia \\ ${ }^{2}$ Oral Cancer Research and Co-ordinating Center (OCRCC), Faculty of Dentistry, University of Malaya, Kuala Lumpur, Malaysia \\ ${ }^{3}$ Cancer Research Initiatives Foundation, Sime Darby Medical Centre, Subang Jaya, Malaysia \\ ${ }^{4}$ Institute of Biological Chemistry, Academia Sinica, Taipei, Taiwan \\ ${ }^{5}$ Center for Cancer and Stem Cell Research, International Medical University, Bukit Jalil, Kuala Lumpur, Malaysia \\ ${ }^{6}$ School of Medicine, Faculty of Medical and Health Sciences, The University of Auckland, New Zealand \\ ${ }^{7}$ School of Medicine, International Medical University, Bukit Jalil, Kuala Lumpur, Malaysia \\ ${ }^{8}$ UPM-MAKNA Cancer Research Laboratory, Institute of Bioscience, Universiti Putra Malaysia, UPM Serdang, Selangor, Malaysia \\ ${ }^{9}$ Faculty of Medicine and Health Sciences, University Tunku Abdul Rahman, Bandar Sungai Long, Selangor, Malaysia \\ ${ }^{10}$ School of Pharmacy, International Medical University, Bukit Jalil, Kuala Lumpur, Malaysia
}

Correspondence to: Chee-Onn Leong, email: cheeonn_leong@imu.edu.my

Keywords: fibroblast growth factor, breast cancer, RNAi screen, FGFR4, FGF19

Received: February 08, 2016

Accepted: April 26, 2016

Published: May 12, 2016

\section{ABSTRACT}

Basal-like breast cancer is an aggressive tumor subtype with poor prognosis. The discovery of underlying mechanisms mediating tumor cell survival, and the development of novel agents to target these pathways, is a priority for patients with basal-like breast cancer. From a functional screen to identify key drivers of basal-like breast cancer cell growth, we identified fibroblast growth factor receptor 4 (FGFR4) as a potential mediator of cell survival. We found that FGFR4 mediates cancer cell survival predominantly via activation of PI3K/AKT. Importantly, a subset of basallike breast cancer cells also secrete fibroblast growth factor 19 (FGF19), a canonical ligand specific for FGFR4. siRNA-mediated silencing of FGF19 or neutralization of extracellular FGF19 by anti-FGF19 antibody (1A6) decreases AKT phosphorylation, suppresses cancer cell growth and enhances doxorubicin sensitivity only in the FGFR4 $^{+}$/FGF19 ${ }^{+}$breast cancer cells. Consistently, FGFR4/FGF19 co-expression was also observed in 82 out of $287(28.6 \%)$ primary breast tumors, and their expression is strongly associated with AKT phosphorylation, Ki-67 staining, higher tumor stage and basal-like phenotype. In summary, our results demonstrated the presence of an FGFR4/FGF19 autocrine signaling that mediates the survival of a subset of basal-like breast cancer cells and suggest that inactivation of this autocrine loop may potentially serve as a novel therapeutic intervention for future treatment of breast cancers.

\section{INTRODUCTION}

Global gene profiling has uncovered previously unrecognized subtype of human breast cancer, including the so-called "triple-negative" or "basal-like" tumors characterized by estrogen/progesterone receptor negativity, lack of HER2 amplification and high frequency of p53 mutation [1-6]. These refractory tumors are therefore insensitive to effective hormonal therapy or herceptinbased therapy and have a poor prognosis compared to other subtypes [1, 7-9].

Although large-scale sequencing of breast cancer genomes has uncovered critical mutations in kinase signaling implicated in basal-like breast cancers for drug development efforts, the functional role of many of these genetic abnormalities remains unclear [10]. It is 
also plausible that other key modulators of the malignant phenotype might not show DNA sequence alterations. To better understand the role of aberrant kinase signaling and identify bona fide molecular targets for drug development in basal-like breast cancers, we undertook a large-scale loss-of-function shRNA screen of the kinome, leading to the identification of fibroblast growth factor receptor 4 (FGFR4) as an essential kinase critical for the proliferation and survival of basal-like breast cancer cells.

FGFR4 belongs to the FGFR protein family comprising of four highly conserved receptor tyrosine kinase members (FGFR1, 2, 3 and 4) and a kinase domain-deficient member (FGFR5 or FGFRL1) [11-14]. In the presence of cofactors such as heparan sulfate proteoglycans (HSPG), FGFRs interact with a wide range of fibroblast growth factors (FGFs) to promote receptor dimerization, autophosphorylation and activation of signaling pathways governing various biological responses involving cell differentiation, proliferation, metastasis, angiogenesis and apoptosis $[11-13,15,16]$. The importance of FGF/FGFR signaling in tumor pathogenesis has been highlighted in large-scale analyses of human cancer genomes, in which components of the FGF/FGFR signaling pathways were the most commonly amplified or mutated in human cancers [12, 17-20].

To date, most of the understanding on the functional role of FGFRs and their signaling pathways has been derived mainly from the study of FGFR1-3. Only limited studies on FGFR4 have been reported so far. Although all family members share significant homology, there are major differences in terms of FGF binding specificity, activation of downstream signaling pathways and tumor-specific genetic alterations $[12,21]$. Unlike FGFR1-3, whose activating mutation plays a central role in tumorigenesis, FGFR4 is rarely mutated in cancer or in other diseases [12, 22]. Although altered expression has been documented in breast, lung, pancreatic and prostate cancers, the specific role for FGFR4 in these cancers is not well established [13].

Here, we demonstrated that FGFR4 is highly expressed in a subset of breast cancer cells and primary tumors. Depletion of endogenous FGFR4 induces tumor-specific lethality in MDA-MB-468 and HCC1937 basal-like breast cancer cells but not in the MCF-7 luminal-like breast cancer cells nor in SKBR3 HER2positive cells. We showed that survival of MDA-MB-468 and HCC1937 is regulated by a constitutively active FGFR4/FGF19 autocrine signaling, which activates downstream PI3K/AKT signaling. Inhibition of FGF19 by siRNA or a neutralizing antibody induced significant apoptotic cell death in an AKT-dependent manner. Importantly, FGFR4, FGF19 and phospho-AKT were found to be co-overexpressed in a subset of basallike breast tumors, suggesting that the FGFR4/FGF19 autocrine loop might be of clinical importance. Together, our results implicate that FGFR4 and FGF19 autocrine signaling may serve as a potential therapeutic target for the treatment of refractory basal-like breast cancers.

\section{RESULTS}

\section{Kinome-wide shRNA library screen identifies $\mathbf{1 5}$ candidate kinases important in regulating basal- like breast cancer cells survival}

The RNAi Consortium (TRC) kinome shRNA library, consisting of 3109 lentiviruses carrying shRNA sequences targeting 673 human kinase genes, was used to screen for the roles of these kinases in mediating the survival of MDAMB-468 breast cancer cells. Each gene is represented by at least 3-5 individual constructs, targeting different regions of the gene sequence. As shown in Figure 1A, a total of $116(3.7 \%)$ shRNA constructs targeting 89 kinases in the TRC kinome library were identified to induce significant growth inhibition (Z-score $<-2$ ) in MDA-MB-468 cells. Out of the 89 candidate kinases, 15 were further identified as hits, based on the criteria that 1) at least two independent shRNAs targeting a specific gene exhibit a $Z$-score of less than -2 , and 2) the $P$-value of Redundant siRNA Activity (RSA) Analysis of each kinase is less than 0.05 (Table 1). Indeed, independent depletion of the endogenous FGFR4, RIPK1, SPHK1, AURKB and PIK3CD significantly reduced MDA-MB-468 cell survival, consistent with the results obtained in the primary screen (Supplementary Figure S1). In addition, several hits, including PLK1 [23, 24], PRKAA1 (or AMPK) [25-27], PIK3CG [28-30] and ERBB3 [31-36] have also been previously shown to mediate cancer cell survival and growth, independently validating the results of our screen.

\section{FGFR4 is overexpressed in a subset of human breast cancer cell lines}

Since FGFR family proteins have been reported to play a functional role in various cancer types [11, 12], and the functional role of FGFR4 in basal-like breast cancers remains elusive [37], we decided to focus on understanding the mechanism underlying FGFR4mediated cell survival in breast cancer cells.

We first evaluated whether FGFR4 is expressed in a panel of breast cancer cell lines consisting of basal-like breast cancer cells (MDA-MB-468, MDA-MB-231 and HCC1937), luminal-like breast cancer cells (T47D and MCF7), HER2 amplified breast cancer cells (SKBR3) and non-transformed breast myoepithelial cells (MCF10A and HMEC). Real-time qPCR shows that FGFR4 mRNA is highly expressed, approximately $10-$ to 2000 fold, in all the breast cancer cells tested as compared to MCF10A and HMEC (Figure 1B). The level of gene expression, however, does not correlate with the protein expression as FGFR4 proteins were only detected in MDA-MB-468, HCC1937, SKBR3 and MCF7 cells, while no FGFR4 protein expression was detected in the MDA-MB-231, T47D, MCF-10A and HMEC cells (Figure 1C). Interestingly, FGFR4 proteins were found 
Table 1: Hits identified from the lentiviral shRNA primary screen

\begin{tabular}{|l|l|c|c|}
\multicolumn{1}{c}{ Kinases } & \multicolumn{1}{c}{ Description } & $4 / 4$ & -11.40 \\
\hline PLK1 & polo-like kinase 1 & $4 / 4$ & -6.83 \\
\hline AURKB & aurora kinase B & $4 / 5$ & -6.20 \\
\hline PIK3CD & phosphatidylinositol-4,5-bisphosphate 3-kinase, catalytic subunit delta & $3 / 3$ & -5.37 \\
\hline FGFR4 & fibroblast growth factor receptor 4 & $4 / 5$ & -4.69 \\
\hline RIPK1 & receptor (TNFRSF)-interacting serine-threonine kinase 1 & $2 / 4$ & -4.07 \\
\hline STK33 & serine/threonine kinase 3 & $3 / 5$ & -3.83 \\
\hline SPHK1 & sphingosine kinase 1 & $3 / 5$ & -3.83 \\
\hline PLK3 & polo-like kinase 3 & $2 / 9$ & -3.08 \\
\hline ERBB3 & erb-b2 receptor tyrosine kinase 3 & $2 / 5$ & -3.00 \\
\hline PIK3CG & phosphatidylinositol-4,5-bisphosphate 3-kinase, catalytic subunit gamma & $2 / 4$ & -2.33 \\
\hline MAP4K3 & mitogen-activated protein kinase kinase kinase kinase 3 & $2 / 5$ & -1.85 \\
\hline EPHA6 & EPH receptor A6 & $2 / 5$ & -1.77 \\
\hline CDKL2 & cyclin dependent kinase like 2 & $2 / 4$ & -1.62 \\
\hline SRPK2 & SRSF protein kinase 2 & $2 / 5$ & -1.59 \\
\hline STK3 & Serine/threonine kinase 3 & 2 \\
\hline
\end{tabular}

${ }^{1}$ Hits indicates the number of shRNA that exhibits Z-score $<-2$ over the total number of shRNA targeting the same gene. ${ }^{2} \log P$-value as determined by RSA.

A
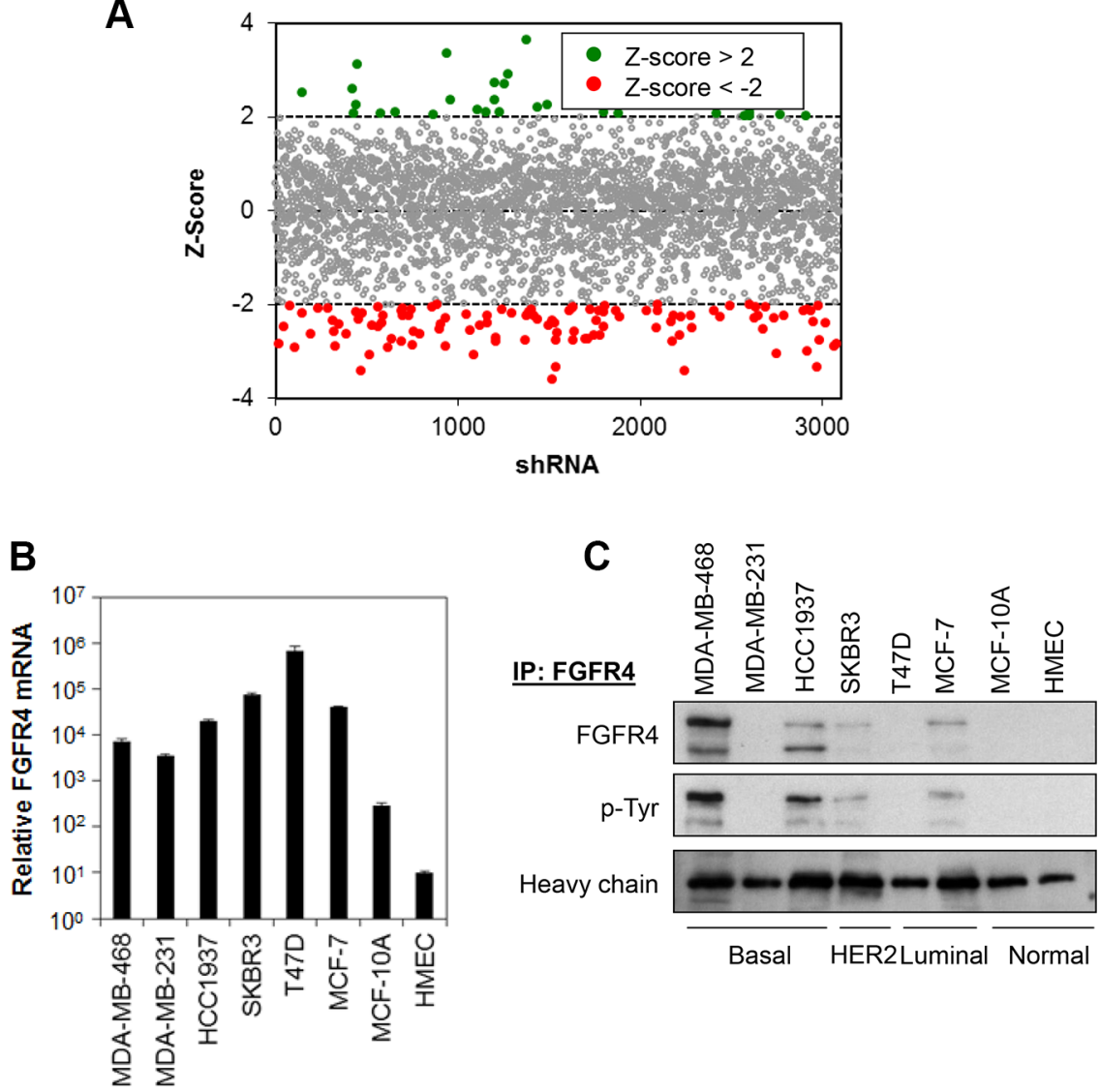

Figure 1: Kinome shRNA library screen identifies FGFR4 as putative target mediating breast cancer cell survival. (A) Kinase shRNA screen scatter plot. Z-scores are plotted on the y-axis against 3109 corresponding shRNAs on the x-axis. Red circled dots represent shRNA that reduces cell proliferation and green circled dots represent shRNA that induces cell proliferation. (B and C) FGFR4 is overexpressed in a subset of breast cancer cells. FGFR4 mRNA and protein expression was determined by qPCR and IP-Western blotting, respectively. Heavy chain serves as loading control. 
to be tyrosine-phosphorylated in cells that express them, suggesting that FGFR4 proteins are constitutively active in these cancer cells.

\section{Knockdown of FGFR4 induces tumor-specific cell death in MDA-MB-468 and HCC1937 cells}

To determine whether depletion of endogenous FGFR4 has any effect on the proliferation and survival of breast cancer cells that exhibit constitutively active FGFR4, we performed lentiviral shRNAs-mediated knockdown of FGFR4 in a panel of breast cell lines. Efficient knockdown of FGFR4 in all breast cell lines by two independent shRNA constructs was demonstrated in IP-Western (Figure 2A). Interestingly, only the basal-like MDA-MB-468 and HCC1937 cells exhibit significant reduction in cell proliferation and induction of apoptosis $(P<0.01$, Student's $t$-test $)$ while no such effect was observed in MCF-7 and SKBR3 that expressed FGFR4, or in cells that have no FGFR4 expression (MDAMB-231, T47D, MCF10A and HMEC) (Figure 2B-2D). This result suggests that FGFR4 is critical for the survival of basal-like MDA-MB-468 and HCC1937 cells but not for the luminal-like MCF-7 cells or the HER2 amplified SKBR3 cells, which also expressed FGFR4. Hence the regulation of tumor-specific cell survival in different subtypes of breast cancer might be contextdependent.

\section{Depletion of FGFR4 inhibits AKT and STAT3 phosphorylation}

FGFR family members have been shown to mediate their biological activities through several signaling pathways, including activation of AKT, STAT3 and ERK1/2 [13]. To evaluate whether the pro-survival effects of FGFR4 in breast cancers cells could be mediated through aberrant activation of these pathways, we analyzed the effects of FGFR4 knockdown on these targets using a panel of phospho-specific antibodies. As shown in Figure 3, depletion of endogenous FGFR4 in MDA-MB-468 and HCC1937 reduced AKT phosphorylations at serine 473 (S473) and threonine 308 (T308). Interestingly, STAT3 phosphorylation was also reduced in $\mathrm{HCC} 1937$, and to a lesser extent in MDA-MB-468 following FGFR4 depletion, while the phosphorylation of ERK1/2 remained unchanged. No such changes were observed in MCF-7 cells, which are insensitive to FGFR4 depletion.

\section{FGFR4 mediates the survival of MDA-MB-468 and HCC1937 cells via AKT signaling pathway}

Since FGFR4 knockdown in MDA-MB-468 and HCC1937 decreases AKT phosphorylation, and AKT is known to play an essential role in cell survival $[38,39]$, we postulate that AKT hyperactivation may sustain the survival of these breast cancer cells. To test this hypothesis, MDA-MB-468 and HCC1937 cells were co-transfected with a constitutively active myristoylated AKT (Myr-AKT) and FGFR4 shRNA followed by evaluation of apoptotic cell death using Annexin V/7-AAD flow cytometry. As shown in Figure 4 and Supplementary Figure S2, ectopic expression of Myr-AKT completely abrogated the apoptotic cell death induced by FGFR4 depletion. In contrast, no such effect was observed in cells overexpressing a constitutively active STAT3 (data not shown), suggesting that FGFR4 mediates the survival of MDA-MB-468 and HCC1937 cells mainly through the AKT signaling pathway.

\section{FGF19 is secreted in a subset of basal-like breast cancer cells}

Next, we sought to investigate the mechanism by which FGFR4 might be constitutively activated in a subset of breast cancer cells. Studies have shown that FGFR4 signaling activation could be triggered by various FGFs, particularly FGF19, which has a unique receptor high-affinity binding specificity towards FGFR4 [40]. We hypothesized that the constitutive activation of FGFR4 in MDA-MB-468 and HCC1937 could be mediated by an autocrine secretion of FGF19 as has been shown in other cancers, such as hepatocellular carcinomas, lung squamous cell carcinomas, and colon adenocarcinomas [41-43]. Indeed, using a highly sensitive and specific FGF19 ELISA assay, we show that the basal-like MDA-MB-468, MDA-MB-231 and HCC1937 secrete a substantial amount of FGF19 (approx. 100-350 pg/mL) (Figure 5A). In contrast, no FGF19 was detected in SKBR3, T47D, MCF7 and MCF-10A cells.

Since FGF19 is secreted in both MDA-MB-468 and HCC1937, and these cells are susceptible to FGFR4knockdown induced apoptosis, it is likely that the constitutive activation of FGFR4 is mediated by autocrine FGF19. To test this hypothesis, we transiently depleted FGF19 from MDA-MB-468, HCC1937, MDA-MB-231 and MCF-10A cells using a FGF19-specific siRNAs pool. Similar to the depletion of FGFR4, depletion of endogenous FGF19 in MDA-MB-468 and HCC1937 cells also significantly reduced cell viability, an observation that is corroborated by the induction of poly ADP ribose polymerase (PARP) cleavage and reduction in AKT phosphorylation (Figure 5B-5D). Consistently, we also observed significant apoptotic cell death as indicated by morphological changes and annexin V/7-AAD staining (Figure 6). No such effect was observed in the FGFR4 ${ }^{-}$ $\mathrm{FGF}^{+} 9^{+} \mathrm{MDA}-\mathrm{MB}-231$ cells or in the FGFR ${ }^{-} / \mathrm{FGF}^{-}{ }^{-}$ MCF-10A cells, suggesting that only cancer cells that co-expressed FGFR4 and FGF19 might be susceptible to FGFR4/FGF19 inhibition. 


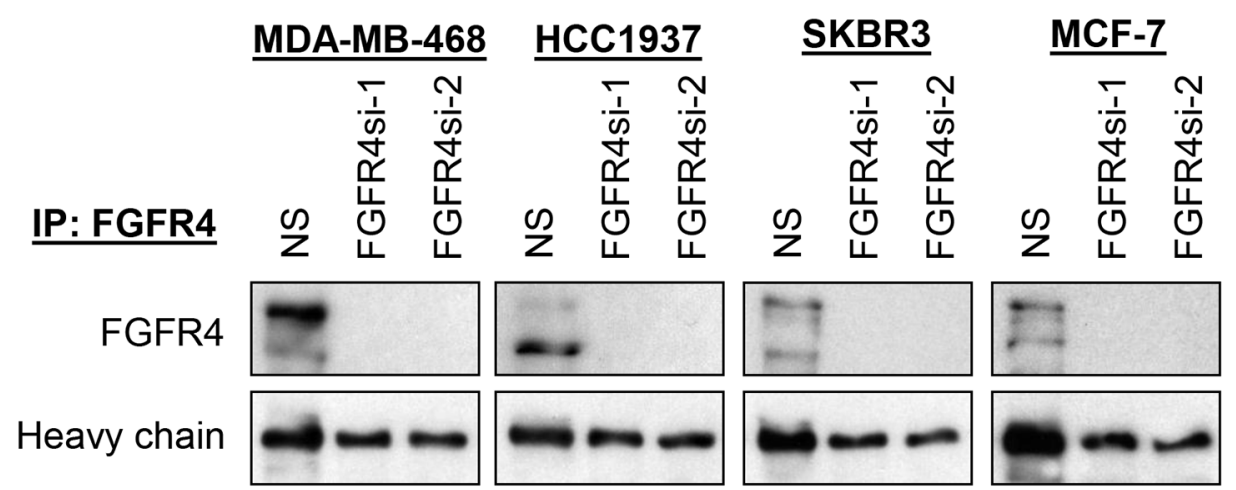

B

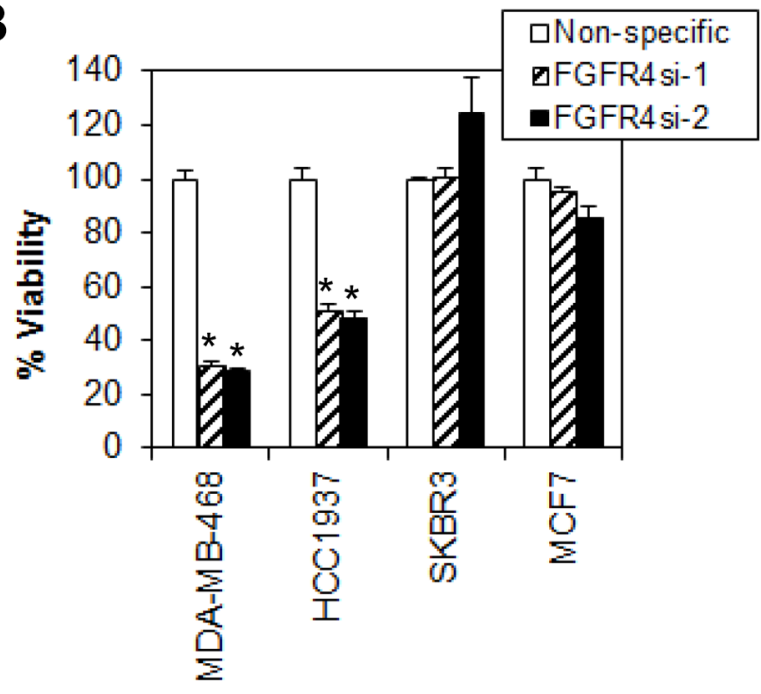

C

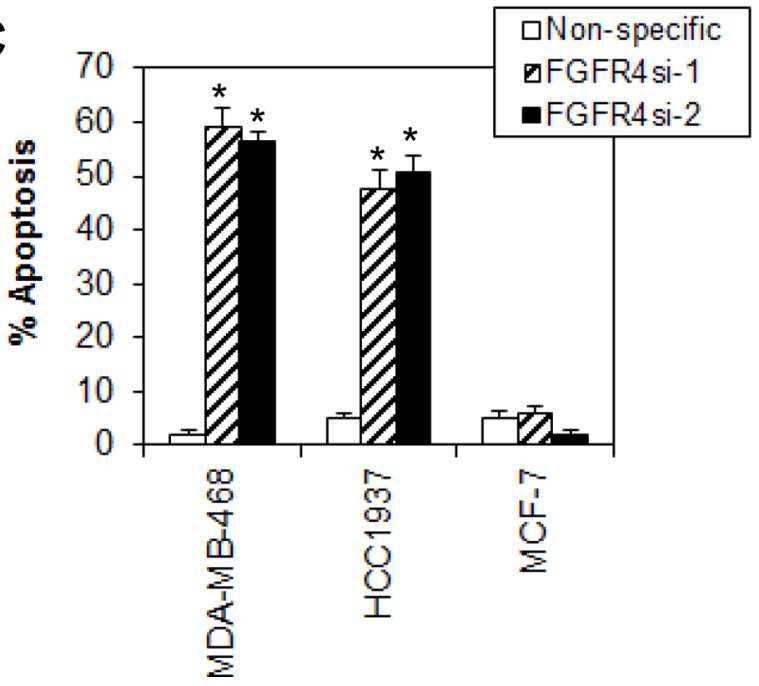

D
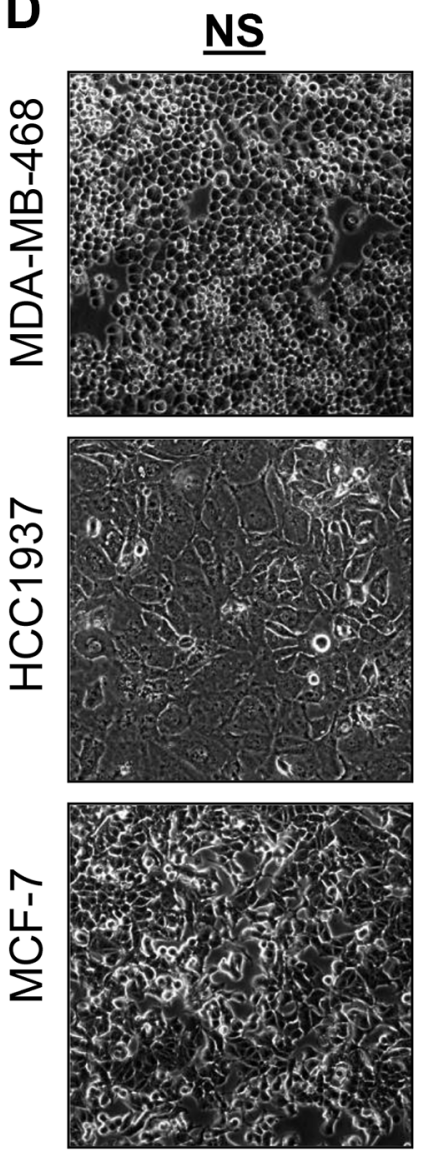

FGFR4si-1
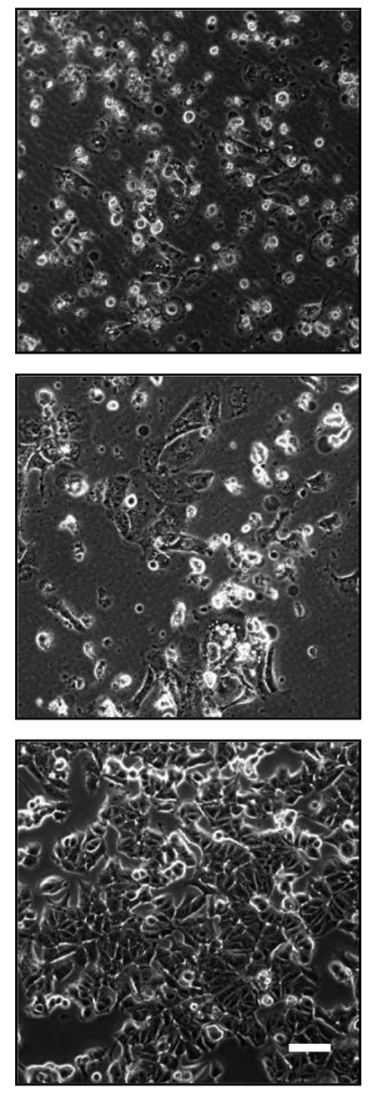

Scale bar $10 \mu \mathrm{m}$

Figure 2: Depletion of endogenous FGFR4 induces tumor-specific cell death in breast cancer cells. (A) Cells were transduced overnight with a non-targeting lentiviral shRNA (NS) and two independent shRNA targeting FGFR4 (FGFR4si-1 and FGFR4si-2). Lysates were collected at $96 \mathrm{~h}$ post-transduction and analyzed by FGFR4 IP-Western blotting. Heavy chain serves as loading control. Note that more than $90 \%$ of endogenous FGFR4 were knocked down by independent shRNA as compared to the nonspecific shRNA control. (B) FGFR4 depletion selectively inhibits the proliferation of MDA-MB-468 and HCC1937. Cell viability was measured using CellTiterGlo assay 5 days post-transduction. (C) FGFR4 knockdown-induced apoptosis in MDA-MB-468 and HCC1937. Cells were collected $72 \mathrm{~h}$ post-transduction and analyzed by annexin V/7-AAD staining. (D) Morphological changes following knockdown of FGFR4 in MDA-MB-468, HCC1937 and MCF-7 cells 5 days post-transduction. Original magnification, $\times 100$. Bars represent means \pm s.d. of three independent experiments. $\left(^{*}\right)$ indicates statistical significance compared with control cells transduced with a non-targeting shRNA (NS) $(P<0.01$, Student's $t$-test $)$. 


\section{A neutralizing anti-FGF19 monoclonal antibody blocks cancer cell growth}

We next sought to test the potential benefit of targeting FGF19 therapeutically in breast cancer cells that co-express FGFR4 and FGF19. We assayed the effect of neutralizing FGF19 on the cancer cell proliferation of MDA-MB-468 and HCC1937 cells using a previously characterized neutralizing antibody specific against FGF19 (1A6) [41]. Cells were treated with $1 \mathrm{~A} 6$ antibody for $72 \mathrm{~h}$ and the cell viability measured by MTT cell proliferation assay. As shown in Figure 7A the anti-FGF19 antibody had a dramatic inhibitory effect on cell proliferation in the $\mathrm{FGFR}^{+} / \mathrm{FGF} 19^{+}$MDA-MB-468 and HCC1937 cells. However, no such inhibitory effect was observed in MCF10A cells, which are FGFR4/FGF19- or in MCF-7 cells, which are FGFR4 ${ }^{+} / \mathrm{FGF} 19$. Furthermore, 1A6 treatment also diminishes the phosphorylation of AKT in both MDA-MB-468 and HCC1937 but not in MCF7, which is consistent with the results observed following FGF19 knockdown by siRNA (Figure 7B).

To further validate whether the effect of 1A6 antiFGF19 antibody was indeed mediated through the FGFR4/
FGF19 autocrine axis, we overexpressed a constitutively active FGFR4 K654E mutant in MDA-MB-468 and HCC1937 cells, followed by quantitation of 1A6-induced apoptosis [44, 45] (Figure 7C). Indeed, the ectopic expression of the constitutively active FGFR4 K645E mutant completely abrogated the apoptotic effects induced by $1 \mathrm{~A} 6$ (Figure 7D and Supplementary Figure S3), suggesting that the effects of 1A6 is dependent on FGFR4/FGF19 signaling, which is consistent with previous studies $[41,43,46]$.

\section{Inhibition of FGFR4/FGF19 autocrine axis enhances doxorubicin sensitivity in breast cancer cells}

Since FGFR4 upregulation and activation has been recently shown to confer chemoresistance in breast cancer cells [47], we asked whether inhibition of the FGFR4/FGF19 axis might enhance chemotherapy sensitivity in cancer cells. To test this hypothesis, we evaluated the effects of the combined application of $1 \mathrm{~A} 6$ with doxorubicin, cisplatin or paclitaxel in the $\mathrm{FGFR}^{+} /$ FGF19+ MDA-MB-468 and HCC1937 cells. As shown in Figure 8, inhibition of FGFR4/FGF19 autocrine axis

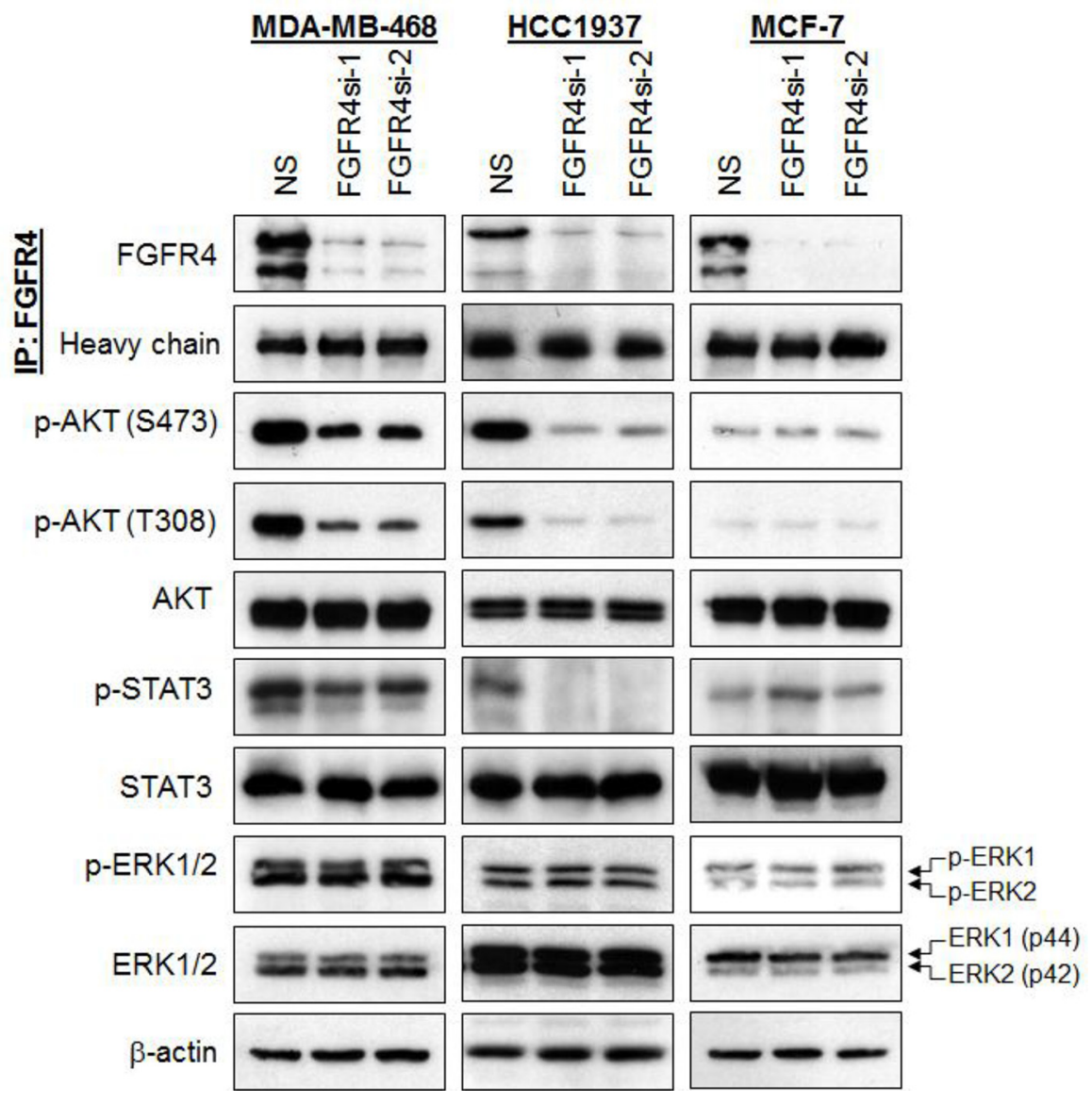

Figure 3: Depletion of endogenous FGFR4 reduces AKT and STAT3 phosphorylation. FGFR4 depletion downregulates AKT and STAT3 phosphorylation in basal-like MDA-MB-468 and HCC1937 but not in MCF-7 cells. Lysates were harvested and assessed by IP-Western analysis $96 \mathrm{~h}$ post-transduction. Heavy chain and $\beta$-actin serve as loading controls. Note the downregulation of phosphoAKT and phospho-STAT3. 
enhances doxorubicin, but not cisplatin or paclitaxel, sensitivity in MDA-MB-468 and HCC1937 breast cancer cells, suggesting that the anti-FGF19 monoclonal antibody might potentiate sensitivity of refractory tumor cells to chemotherapy.

\section{FGFR4 and FGF19 are co-expressed in a subset of primary breast tumors}

Finally, to determine whether FGFR4/FGF19 co-expression is present in primary breast tumors, we stained tissue microarrays of primary human breast cancer samples diagnosed with invasive ductal carcinoma
(IDC) for FGFR4 and FGF19, and compared this with AKT phosphorylation (Figure 9). As shown in Table 2, approximately $26.5 \%$ of the tumors were FGFR4-/ FGF $19-, 45 \%$ of the tumors were positive for either FGFR4 or FGF19, and $28.6 \%$ of the primary IDC exhibit co-expression of FGFR4 and FGF19. Importantly, FGFR4/FGF19 co-expression was associated with AKT phosphorylation $(P<0.001)$, Ki-67 staining $(P=0.005)$ and higher tumor stage $(P<0.001)$ (Table 3$)$. Interestingly, FGFR4/FGF19 co-expression was also strongly associated with basal-like phenotype, with up to $43.6 \%$ of the triple negative (ER/PR/HER2 negative) tumors and $55.9 \%$ of the $\mathrm{CK} 5 / 6$ positive tumors
A

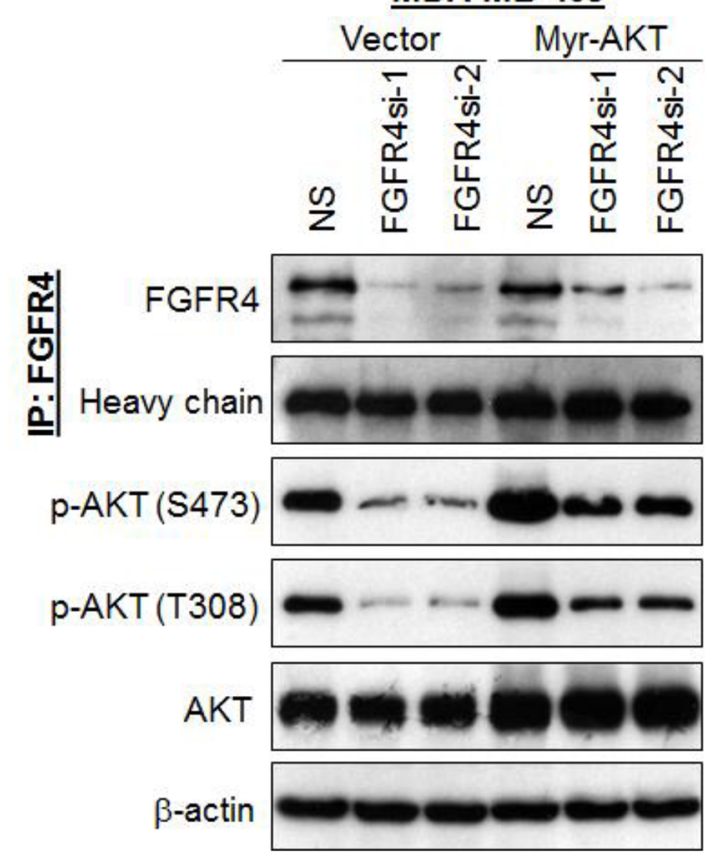

B

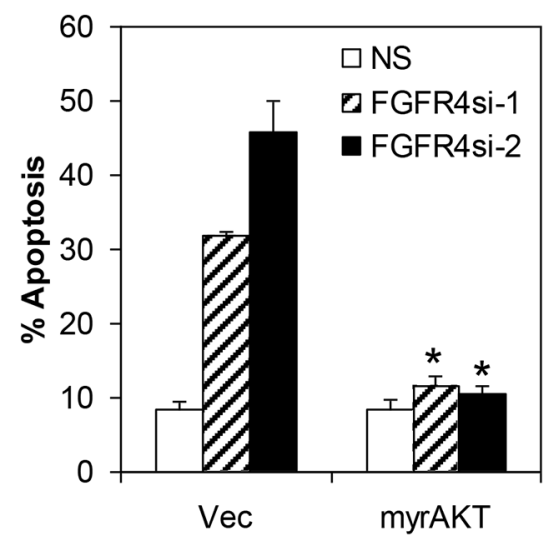

HCC1937
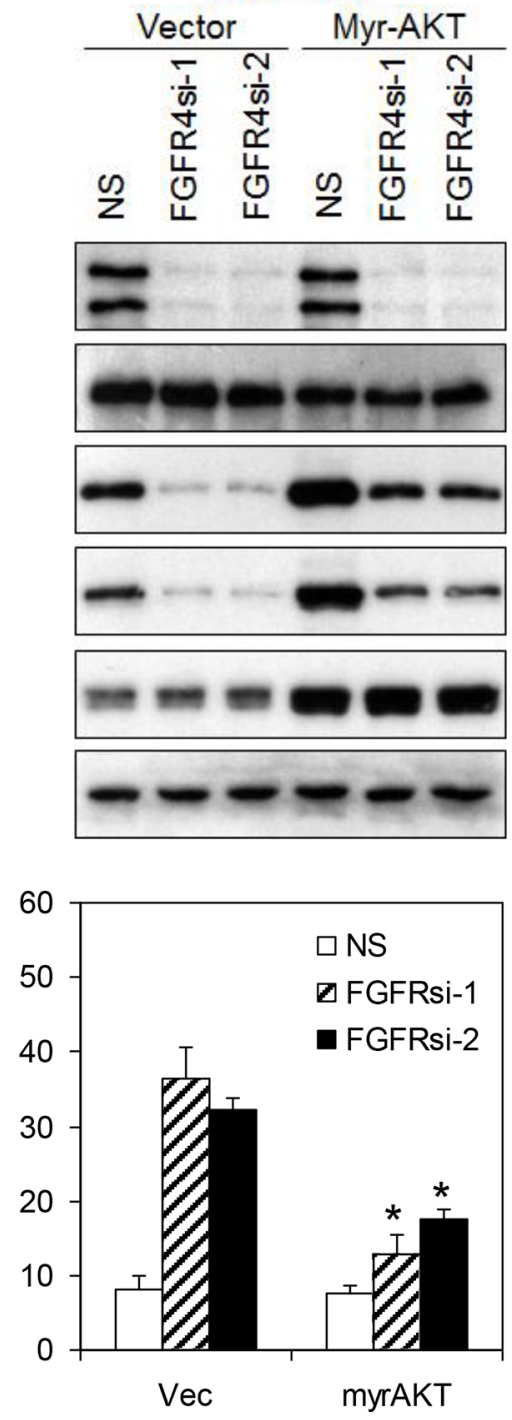

Figure 4: FGFR4 mediates cells survival via activation of AKT signaling pathway. (A) Ectopic expression of constitutively active AKT (Myr-AKT) rescued apoptotic cell death induced by FGFR4 knockdown. Cells were transiently transfected with myristoylated AKT concurrently with either NS or FGFR4 targeting shRNAs. Lysates were collected $72 \mathrm{~h}$ post-transfection and analyzed by IP-Western blotting. (B) Ectopic expression of myristoylated AKT abrogated FGFR4-depletion induced cell death in basal-like MDA-MB-468 and HCC1937 cells. Cells were transfected as in (A). Apoptosis was analyzed by annexin V/7-AAD staining. Bars represent means \pm s.d. of three independent experiments. $\left(^{*}\right)$ indicates statistical significance compared with vector control cells following FGFR4 depletion $(P<0.01$, Student's $t$-test $)$. 
Table 2: Expression of FGFR4 and FGF19 in primary breast tumors

\begin{tabular}{|l|c|c|c|}
\hline \multicolumn{3}{c}{ FGFR4- } & FGFR4+ \\
\hline FGF19- & $76(26.5 \%)$ & $43(15.0 \%)$ & $0.033^{*}$ \\
\hline FGF19+ & $86(30.0 \%)$ & $82(28.6 \%)$ & \\
\hline
\end{tabular}

${ }^{\psi}$ Chi-square test; $* P<0.05$.

A

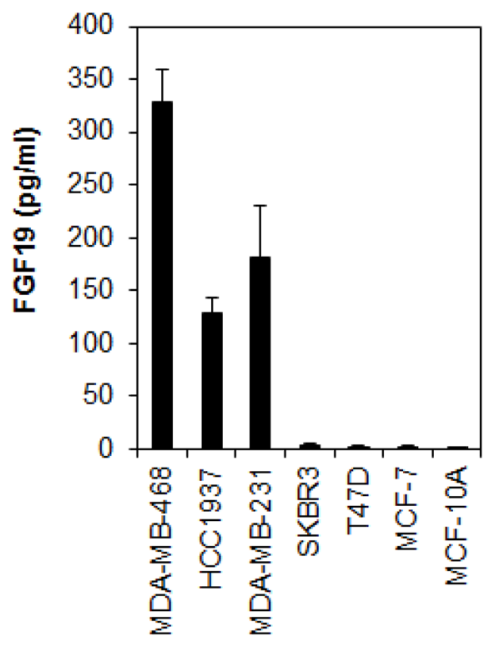

B

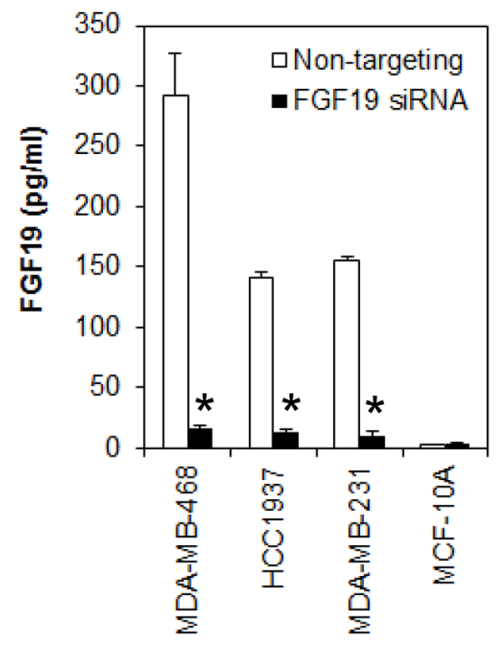

C

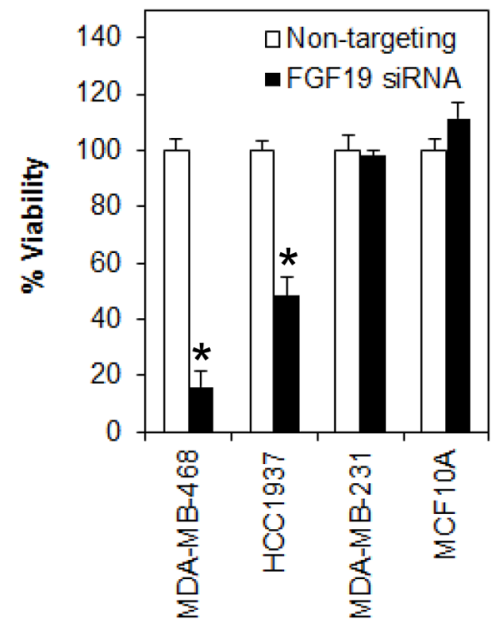

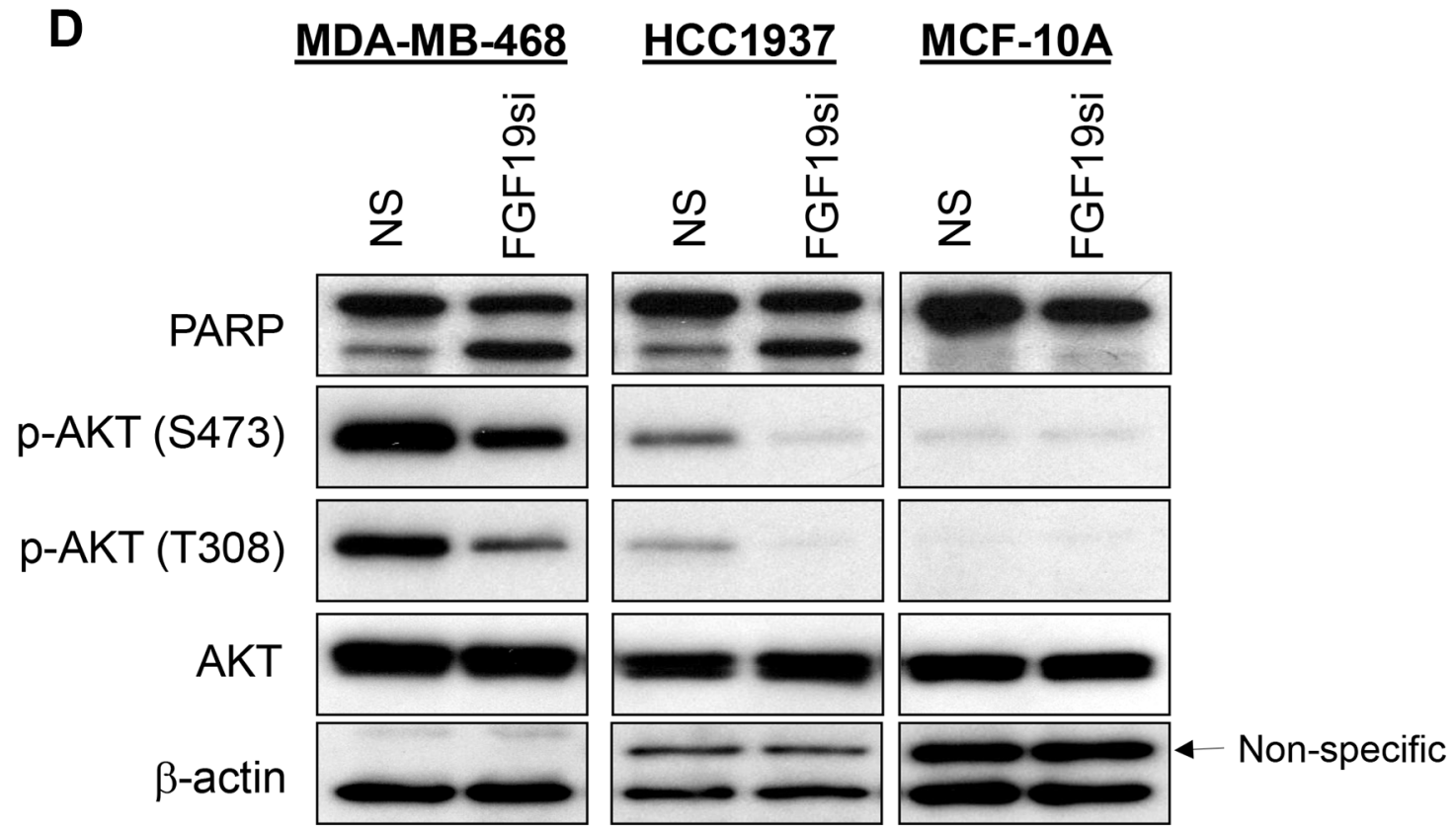

Figure 5: FGF19 autocrine signaling promotes cell survival in FGFR4/FGF19 co-expressed cells. (A) FGF19 is secreted in a subset of breast cancer cells. Supernatant was collected from all pre-confluent cells following $72 \mathrm{~h}$ of seeding and FGF19 secretion was measured using ELISA immunoassay. Note that no FGF19 was detected in the luminal-like (MCF-7, T47D and SKBR3) breast cancer cells nor in non-transformed myoepithelial cells (MCF-10A). (B and C) Depletion of FGF19 induces growth inhibition in the $\mathrm{FGFR}^{+} / \mathrm{FGF} 19^{+}$MDA-MB-468 and HCC1937 but not in the FGFR4-/FGF19+ MDA-MB-231 or in the FGFR4-/FGF19- MCF-10A $^{+}$ non-transformed myoepithelial cells. Cells were transfected with a FGF19 smart pool siRNA as in (A) and the cell viability measured by CellTiter-Glo assay 3 days post-transfection. Bars represent means \pm s.d. of three independent experiments. (*) indicates statistical significance compared with control cells transfected with a non-targeting siRNA $(P<0.01$, Student's $t$-test). (D) Depletion of FGF19 downregulates AKT phosphorylation. 
Table 3: Association of FGFR4/FGF19 co-expression with clinicopathological features of invasive breast cancers

\begin{tabular}{|c|c|c|c|c|c|c|c|}
\hline & \multicolumn{4}{|c|}{ FGFR4/FGF19 Co-expression } & \multirow{2}{*}{\multicolumn{2}{|c|}{ Total $(n=287)$}} & \multirow[b]{2}{*}{$P$-Value ${ }^{\Psi}$} \\
\hline & \multicolumn{2}{|c|}{ No $(n=205)$} & \multicolumn{2}{|c|}{ Yes $(n=82)$} & & & \\
\hline \multicolumn{8}{|l|}{ TNM stage } \\
\hline $\mathrm{I}$ & 5 & $(1.7 \%)$ & 4 & $(1.4 \%)$ & 9 & $(3.1 \%)$ & $<0.001 *$ \\
\hline II & 182 & $(63.4 \%)$ & 23 & $(8.0 \%)$ & 205 & $(71.4 \%)$ & \\
\hline III & 12 & $(4.2 \%)$ & 38 & $(13.2 \%)$ & 50 & $(17.4 \%)$ & \\
\hline IV & 6 & $(2.1 \%)$ & 17 & $(5.9 \%)$ & 23 & $(8.0 \%)$ & \\
\hline \multicolumn{8}{|l|}{ ER/PR/HER2 status } \\
\hline ER/PR-, HER2- & 53 & $(18.5 \%)$ & 41 & $(14.3 \%)$ & 94 & $(32.8 \%)$ & $<0.001 * \#$ \\
\hline ER/PR-, HER2+ & 33 & $(11.5 \%)$ & 13 & $(4.5 \%)$ & 46 & $(16.0 \%)$ & \\
\hline ER/PR+, HER2- & 96 & $(33.4 \%)$ & 20 & $(7.0 \%)$ & 116 & $(40.4 \%)$ & \\
\hline ER/PR,+ HER2+ & 23 & $(8.0 \%)$ & 8 & $(2.8 \%)$ & 31 & $(10.8 \%)$ & \\
\hline \multicolumn{8}{|l|}{ CK5/6 } \\
\hline Negative & 164 & $(57.1 \%)$ & 30 & $(10.5 \%)$ & 194 & $(67.6 \%)$ & $<0.001^{*}$ \\
\hline Positive & 41 & $(14.3 \%)$ & 52 & $(18.1 \%)$ & 93 & $(32.4 \%)$ & \\
\hline \multicolumn{8}{|l|}{ pAKT } \\
\hline Negative & 180 & $(62.7 \%)$ & 52 & $(18.1 \%)$ & 232 & $(80.8 \%)$ & $<0.001^{*}$ \\
\hline Positive & 25 & $(8.7 \%)$ & 30 & $(10.5 \%)$ & 55 & $(19.2 \%)$ & \\
\hline \multicolumn{8}{|l|}{ Ki-67 } \\
\hline Low & 114 & $(39.7 \%)$ & 31 & $(10.8 \%)$ & 145 & $(50.5 \%)$ & $0.005^{*}$ \\
\hline High & 89 & $(31.0 \%)$ & 51 & $(17.8 \%)$ & 140 & $(48.8 \%)$ & \\
\hline Unknown & 2 & $(0.7 \%)$ & 0 & $(0.0 \%)$ & 2 & $(0.7 \%)$ & \\
\hline \multicolumn{8}{|l|}{ p53 } \\
\hline Negative & 81 & $(28.2 \%)$ & 37 & $(12.9 \%)$ & 118 & $(41.1 \%)$ & 0.826 \\
\hline Positive & 93 & $(32.4 \%)$ & 40 & $(13.9 \%)$ & 133 & $(46.3 \%)$ & \\
\hline Unknown & 31 & $(10.8 \%)$ & 5 & $(1.7 \%)$ & 36 & $(12.5 \%)$ & \\
\hline \multicolumn{8}{|l|}{ EGFR } \\
\hline Negative & 142 & $(49.5 \%)$ & 58 & $(20.2 \%)$ & 200 & $(69.7 \%)$ & 0.967 \\
\hline Positive & 57 & $(19.9 \%)$ & 23 & $(8.0 \%)$ & 80 & $(27.9 \%)$ & \\
\hline Unknown & 6 & $(2.1 \%)$ & 1 & $(0.4 \%)$ & 7 & $(2.4 \%)$ & \\
\hline
\end{tabular}

${ }^{\psi}$ Chi-square test;

$* P<0.05$;

"Statistical significance between triple-negative (ER/PR-, HER2-) vs non-triple negative (ER/PR-, HER2+; ER/PR+, HER2; and ER/PR+, HER2 + ) breast cancers $(P<0.01)$.

exhibiting FGFR4/FGF19 co-expression. In contrast, no significant association between FGFR4/FGF19 coexpression and EGFR or p53 was observed, indicating that the FGFR4/FGF19 axis is independent of EGFR or p53 signaling.

Collectively, our results demonstrated the existence of a FGFR4-FGF19 autocrine loop, which could potentially be developed as a therapeutic target for future treatment of refractory basal-like breast cancers.

\section{DISCUSSION}

The significance of FGFs/ FGFRs signaling deregulation in breast cancers has been documented in several studies [13, 48, 49]. However, the exact mechanism by which each FGFR family protein might mediate the survival and proliferation of cancer cells remained unknown. Through an unbiased lentiviral shRNA kinome library screen, we identified FGFR4 as a 
receptor tyrosine kinase that is required for the survival of a subset of basal-like breast cancer cells. We found that FGFR4 is overexpressed in a subset of breast cancer cell lines but not in the normal myoepithelial cells. Of note, the FGFR4 protein was found to be phosphorylated in breast cancer cells that express it, suggesting that FGFR4 might be constitutively active in these cancer cells. These results are consistent with previous studies, which show that FGFR4 is overexpressed in 10-30\% of breast cancers [50-52].
Unlike FGFR1-3, where activating mutations and genetic amplifications are commonly associated with tumor progression, FGFR4 is rarely mutated in human cancers [13, 53, 54]. Most of the reports regarding FGFR4 and cancers have focused mainly on a common singlenucleotide polymorphism (SNP), FGFR4 Gly388Arg, of which at least one copy is present in approximately $30-50 \%$ of the population $[13,55]$. This SNP does not seem to increase the incidence of cancer, but has been reported to be associated with poor prognosis in multiple
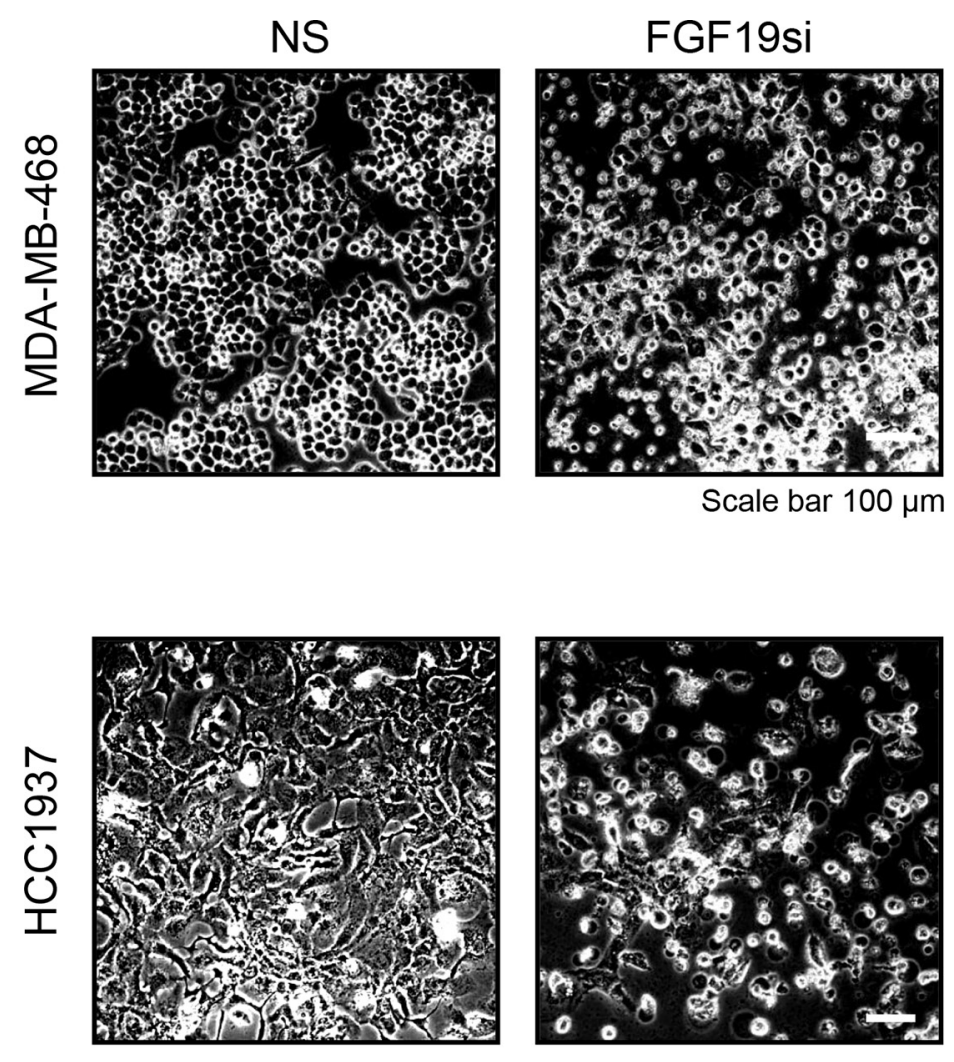

Scale bar $10 \mu \mathrm{m}$
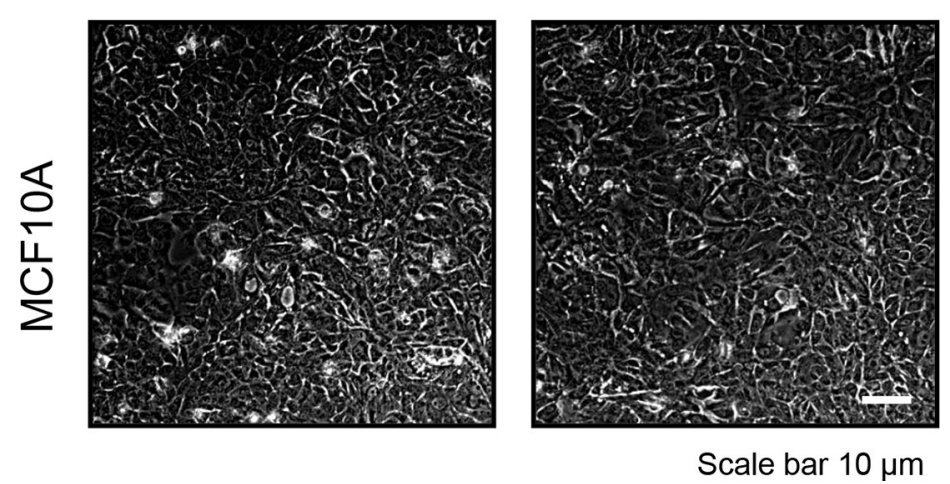
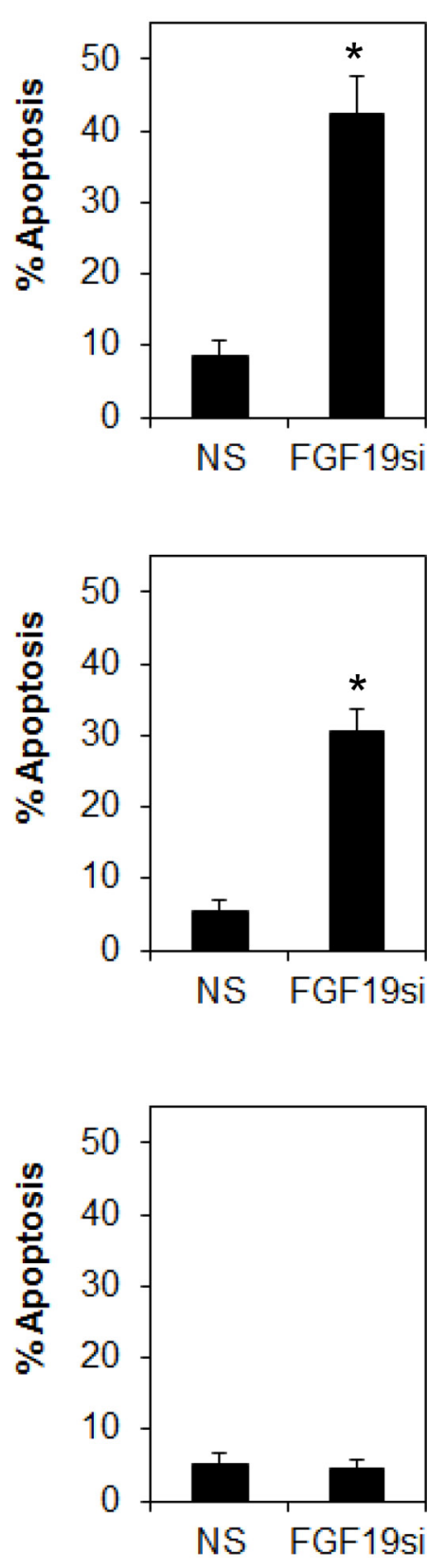

Figure 6: FGFR4-FGF19 autocrine signaling promotes survival in MDA-MB-468 and HCC1937. Cells were treated as in Figure 5. Morphological changes were recorded at 100X magnification, $72 \mathrm{~h}$ post-transfection. Apoptosis was determined by annexin $\mathrm{V} / 7-\mathrm{AAD}$ staining. Bars represent means \pm s.d. of three independent experiments. $\left.{ }^{*}\right)$ indicates statistical significance compared with nontargeting siRNA $(P<0.01$, Student's $t$-test). 
cancer types, including breast cancer, and is thought to promote cancer cell motility and invasion or resistance to chemotherapy $[20,47,56-61]$. However, sequence analysis of breast cancer cell lines did not show any correlation between the Gly388 SNP genotype with FGFR4 mRNA or protein expression levels, suggesting that FGFR4 overexpression might have a different functional role in the pathogenesis of breast cancer (Supplementary Table S1).

A

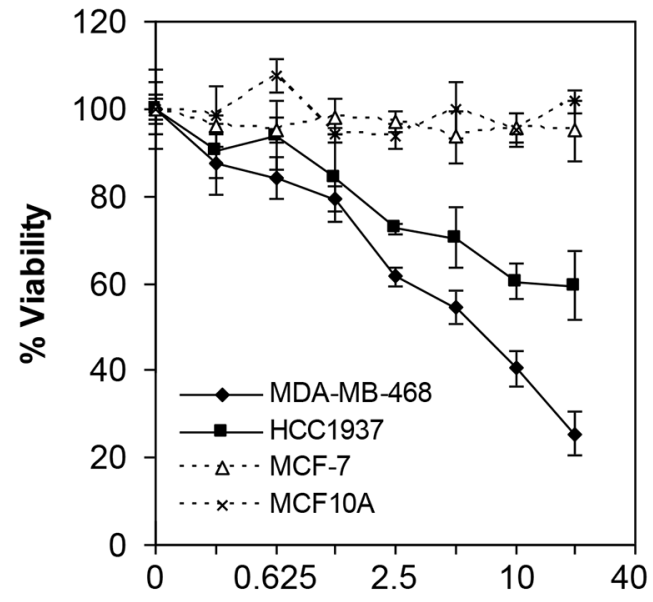

Anti-FGF19 $(\mu \mathrm{g} / \mathrm{ml})$

C

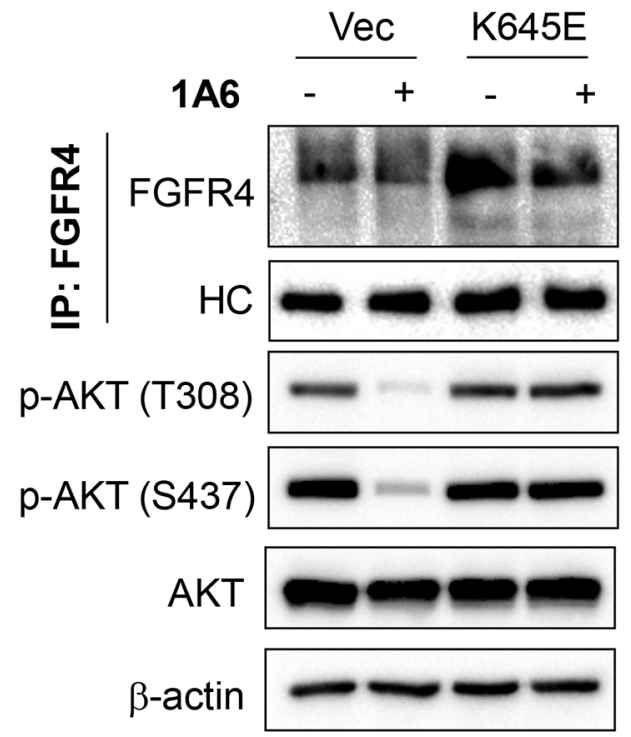

To test whether FGFR4 plays a functional role in mediating the survival of basal-like breast cancer cells, gene knockdown was performed using two independent lentiviral shRNAs targeting the endogenous FGFR4 in a panel of breast cell lines. Indeed, depletion of the endogenous FGFR4 in the basal-like MDA-MB-468 and HCC1937 induces a significant amount of growth inhibition and apoptosis, while no such effects were observed in MDA-MB-231, T47D, MCF-10A and HMEC

B

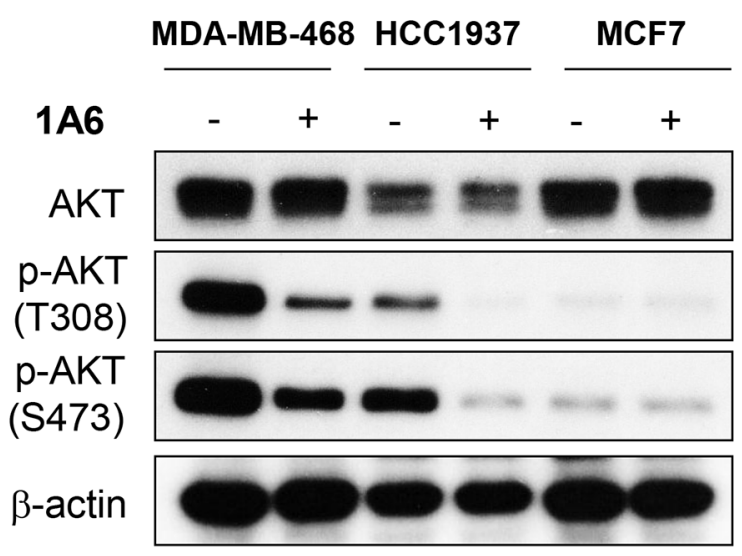

D

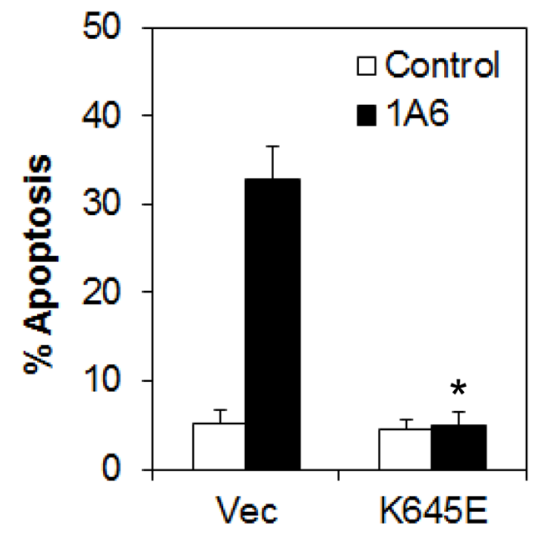

Figure 7: Inactivation of autocrine FGF19 by monoclonal antibody abrogates FGFR4-mediated survival of breast cancer cells. (A) Neutralization of FGF19 by an anti-FGF19 antibody, 1A6, inhibits cell growth in FGFR4 $/$ FGF19 ${ }^{+}$MDA-MB-468 and HCC1937 cells, but not in FGFR4+FGF19- MCF-7 cells or in FGFR4-/FGF19- MCF-10A cells. Cells were treated with various concentrations of $1 \mathrm{~A} 6$ for $72 \mathrm{~h}$ and the cell viability was determined by CellTiter-Glo assay. (B) $1 \mathrm{~A} 6$ attenuates AKT phosphorylation. Cells were treated with $10 \mu \mathrm{g} / \mathrm{mL}$ of $1 \mathrm{~A} 6$ for $48 \mathrm{~h}$ and lysates were collected for Western blot analyses. (C and D) The apoptotic effect of $1 \mathrm{~A} 6$ is dependent on inhibition of FGFR4/FGF19 signaling. Cells were transfected with vector or constitutively active FGFR4 K645E mutant for $24 \mathrm{~h}$ followed by treatment with $10 \mu \mathrm{g} / \mathrm{mL}$ of $1 \mathrm{~A} 6$ for $72 \mathrm{~h}$. Apoptosis was analyzed by annexin V/7-AAD staining. Bars represent means \pm s.d. of three independent experiments. $\left(^{*}\right)$ indicates statistical significance compared with vector control cells following 1 A6 treatment $(P<0.01$, Student's $t$-test). 

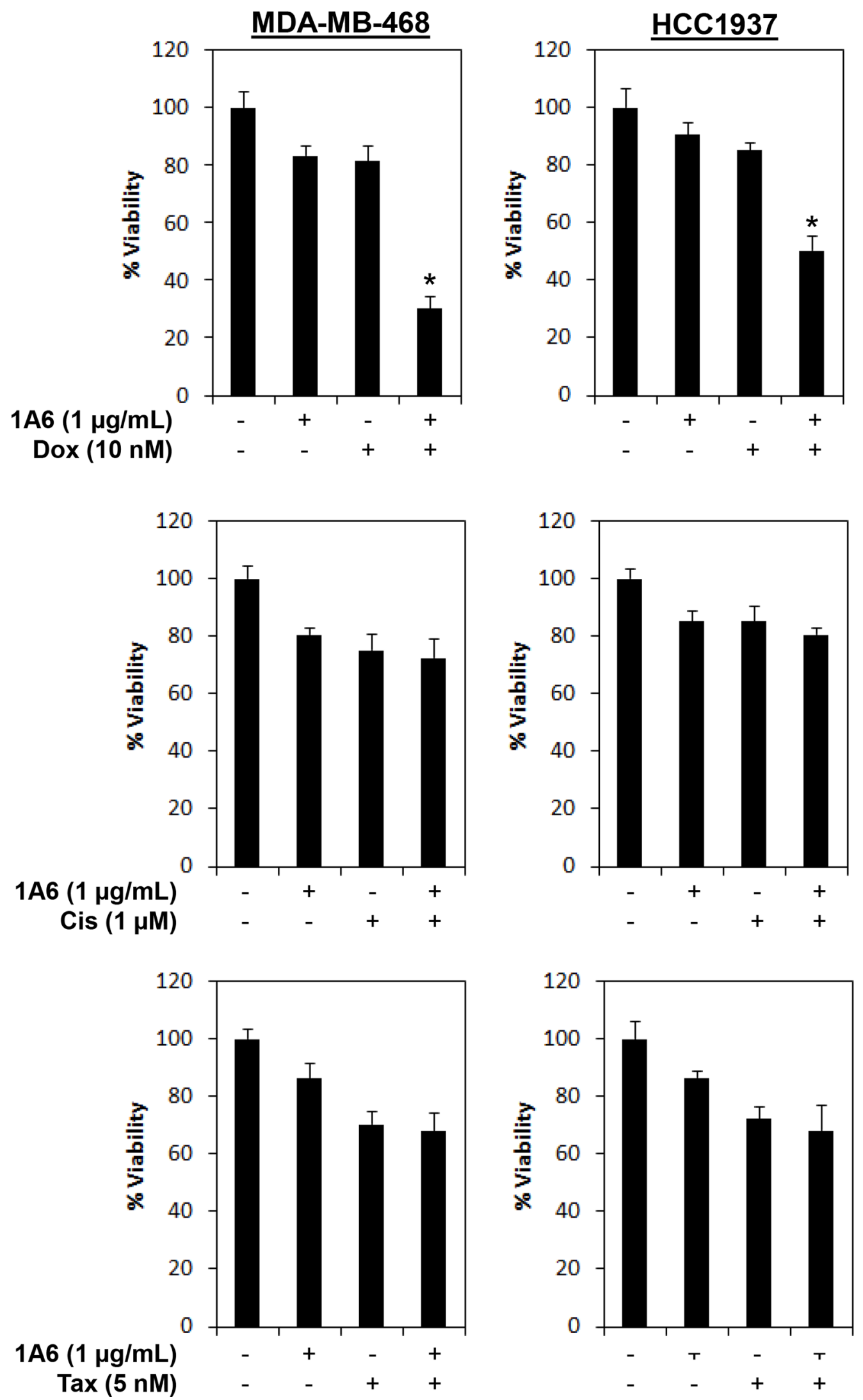

Figure 8: Inhibition of FGF19 synergizes doxorubicin sensitivity in FGFR4/FGF19 co-expressed breast cancer cells. Cells were treated with $1 \mu \mathrm{g} / \mathrm{mL}$ of $1 \mathrm{~A} 6$ and/or $10 \mathrm{nM}$ of doxorubicin (Dox), $1 \mu \mathrm{M}$ of cisplatin (Cis) or $5 \mathrm{nM}$ of Paclitaxel (Tax). Cell viability was determined by CellTiter-Glo assay $72 \mathrm{~h}$ following treatments. $\left(^{*}\right)$ indicates statistical significance compared with $1 \mathrm{~A} 6$ or doxorubicin treated cells $(P<0.01$, Student's $t$-test $)$. 
cells, which do not express FGFR4. Intriguingly, depletion of endogenous FGFR4 has no such effect on the luminallike MCF-7 and HER2-amplified SKBR3 cells, suggesting that FGFR4 mediates cancer cell survival in a cell contextdependent manner.

Activation of FGFRs has been shown to activate AKT, ERK1/2 and STAT3 signaling [13, 62]. Activated FGFRs phosphorylates FRS2 on several sites, allowing the recruitment of the adaptor proteins son of sevenless (SoS) and growth factor receptor bound 2 (GRb2) to activate RAS and the downstream RAF and MAPK pathways. A separate complex involving GRb2-associated-binding protein 1 (GAb1) recruits a complex, which includes PI3K, and this activates an AKT-dependent anti-apoptotic pathway [63]. Activation of FGFRs also phosphorylates and activates STAT3 directly, independent of FRS2 [45].

To test whether the pro-survival effects of FGFR4 are mediated by MAPK, AKT and/or STAT3 pathways, we investigated the effects of FGFR4 depletion on these pathways. Our results demonstrated that depletion of FGFR4 reduced AKT and STAT3 phosphorylation while the phosphorylation of ERK1/2 remained unchanged. Importantly, ectopic expression of a myristoylated AKT, but not the constitutively active STAT3, significantly abrogated apoptosis induced by FGFR4 knockdown, suggesting that the pro-survival effects of FGFR4 are mediated mainly through the PI3K/AKT signaling.
These results are consistent with a recent study that shows that inhibition of the FGFR activity by TKI258 significantly inhibits AKT activity and AKT-dependent cell proliferation in murine breast cancer cells [64].

Since FGFR4 is rarely mutated and the G388 polymorphism is not associated with the pro-survival activities of FGFR4, we asked whether the constitutively active FGFR4 signaling in cancers could be activated by an autocrine signaling loop, as has been demonstrated in other FGFR family members [65]. To test this hypothesis, the protein expression of a highly specific ligand of FGFR4, FGF19, was evaluated by ELISA. Our results show that the basal-like breast cancer cell lines express high levels of secreted FGF19 as compared to luminal-like breast cancers or non-transformed mammary myoepithelial cells. Phenotypic and cell viability assessment following depletion of FGF19 also demonstrated that FGF19mediated downstream signaling is crucial for the survival of basal-like breast cancer cells that co-express FGFR4 and FGF19 (MDA-MB-468 and HCC1937), as depletion of FGF19 by siRNA or anti-FGF19 monoclonal antibody (1A6) inhibits cell proliferation and induces apoptosis in these cells. In stark contrast, no such effects were observed in the FGFR4 ${ }^{+} / \mathrm{FGF} 19^{-} \mathrm{MCF}-7$ cells or in the FGFR4\% FGF19+ MDA-MB-231 cells. Of note, the mechanism by which FGFR4 is constitutively active in the absence of FGF19 in MCF-7 and SKBR3 cells remains to be further
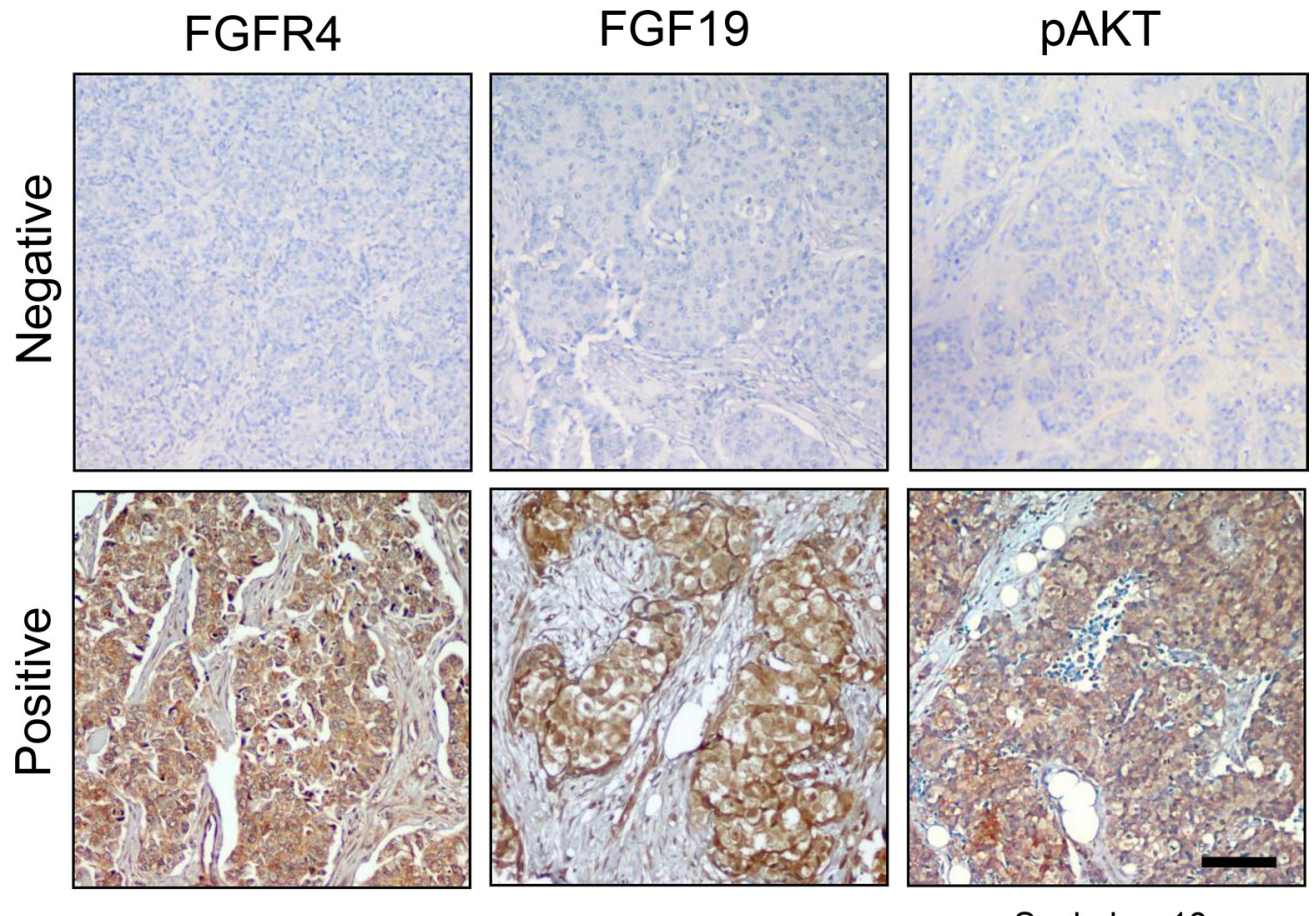

Scale bar $10 \mu \mathrm{m}$

Figure 9: FGFR4/FGF19 co-expression is associated with AKT phosphorylation in a subset of breast cancer cells. Immunohistochemistry of representative primary tumors. Photomicrographs demonstrate low and high expression of FGFR4, FGF19 and phospho-AKT (S473). Note the positive staining for FGFR4, FGF19 and phospho-AKT in the cytoplasm of most tumor cells, but not in the nucleus. The association of FGFR4/FGF19 expression with clinicopathological features are presented in Tables 2 and 3 . Original magnification, 100X. 
investigated. It is likely that aberrant expression of other FGFs, such as FGF1 and FGF3, which have been shown to bind FGFR4 at high concentration [66], might regulate the phosphorylation of FGFR4 in these cells. Regardless, the knockdown of FGFR4 has no effect on MCF-7 and SKBR3 cells, suggesting that FGFR4 signaling is dispensable in mediating the survival of these cells.

Since hyperactivation of FGFR4 signaling has also been shown to confer chemoresistance in breast, gastric and colorectal cancer cells [47, 67-70], we hypothesized that the combined application of anti-FGF19 neutralizing antibody and chemotherapeutic agents might further increase the apoptosis rate of cancer cells. Indeed, inhibition of FGFR4/FGF19 autocrine signaling synergizes with doxorubicin (but not cisplatin or paclitaxel) to enhance sensitivity in basal-like breast cancer cells, highlighting the potential of using an anti-FGF19 monoclonal antibody as a therapeutic for breast cancer cells that co-express FGFR4 and FGF19. Whether the specific synergism between FGFR4/FGF19 inhibition and doxorubicin is dependent on PI3K/AKT signaling remains to be further investigated.

Finally, using a panel of well-validated tissue microarray, we show that a subset of primary breast tumors coexpresses FGFR4 and FGF19. Importantly, the co-expression of FGFR4/FGF19 is significantly associated with AKT phosphorylation, Ki-67 staining, higher tumor stage and basallike phenotype (triple-negative and CK $5 / 6$ positivity) in breast cancers. In contrast, no association between FGFR4/FGF19 co-expression and EGFR or p53 was observed, suggesting that FGFR4/FGF19 might mediate cancer cell survival through a mechanism independent of EGFR or p53 signaling.

In summary, our results demonstrate that the FGFR4/FGF19 autocrine signaling mediates the survival of a subset of basal-like breast cancer cells through activation of $\mathrm{PI} 3 \mathrm{~K} / \mathrm{AKT}$ signaling. Inhibition of the FGFR4/FGF19 signaling induces tumor-specific cell death in cancer cells that express them. As such, targeting the FGFR4/FGF19 autocrine loop represents a potential therapeutic strategy for future management of refractory basal-like breast cancers.

\section{MATERIALS AND METHODS}

\section{Materials}

Constitutively active myristoylated AKT (Addgene plasmid \# 9008), STAT3 (Addgene plasmid \# 24983) were a gift from William Sellers [71] and Linzhao Cheng [72], respectively. FGF19 antibody (clone 1A6) was provided by Genentech Inc., USA. The constitutively active FGFR4-K645E has been described previously [45].

\section{Cell lines and cell culture}

The human breast cancer cell lines MDA-MB-468, MDA-MB-231, HCC1937, SKBR3, T47D and MCF7 were purchased from American Type Culture Collection
(ATCC) and maintained in RPMI-1640 medium containing $10 \%$ fetal bovine serum, $100 \mathrm{IU} / \mathrm{ml}$ penicillin, and $100 \mu \mathrm{g} / \mathrm{ml}$ streptomycin (Sigma-Aldrich, St. Louis, MO, USA). The non-transformed human mammary epithelial cells MCF10A were cultured in DMEM-F12 (Invitrogen Carlsbad, CA) supplemented with 5\% horse serum, $20 \mathrm{ng} / \mathrm{ml}$ EGF, $0.5 \mu \mathrm{g} / \mathrm{ml}$ hydrocortisone, $10 \mu \mathrm{g} / \mathrm{ml}$ insulin, $100 \mathrm{IU} / \mathrm{ml}$ penicillin, and $100 \mu \mathrm{g} / \mathrm{ml}$ streptomycin, while HMEC was grown in HuMEC Ready Media (Invitrogen, Carlsbad, CA). All cells were maintained at $37^{\circ} \mathrm{C}$ in $5 \%$ $\mathrm{CO}_{2}$. Cells were passaged for less than 6 months and no further authentication was performed by the authors.

\section{Lentiviral human kinase shRNA library screen}

The role of protein kinases was examined using the MISSION LentiExpress ${ }^{\mathrm{TM}}$ Human Kinases shRNA Library (Sigma, St Louis, MO). Briefly, MDA-MB-468 basal-like breast cancer cells were seeded at a density of 1500 cells/ well in a 96-well plate overnight. Cells were transduced with lentiviral particles at multiplicities of infection (MOI) of approximately 1.5 in the presence of $7.5 \mu \mathrm{g} / \mathrm{ml}$ polybrene (Sigma, St Louis, MO) for $18 \mathrm{~h}$ in $37^{\circ} \mathrm{C}, 5 \%$ $\mathrm{CO}_{2}$. Medium was changed and the number of viable cells was determined using CellTiterGlo assay (Promega, Madison, WI) 5 days post-transduction. Controls include lentiviral particles carrying an empty vector (pLKO.1-puro), a non-target shRNA (NS) or a GFPexpressing lentiviral construct to monitor transduction efficiency and well-to-well difference. All data were normalized against non-target shRNA controls. Hits were identified based on: 1) at least two independent shRNAs targeting a specific gene exhibit a $Z$-score of less than -2 ; and 2) the $P$-value of Redundant siRNA Activity (RSA) Analysis of each kinase is less than 0.05 [73].

\section{Quantitative real-time PCR (qPCR) analysis}

Gene expression levels were measured by realtime qPCR as described previously [74, 75]. The specific forward and reverse primer sequences are shown in Supplementary Table S2. The conditions for all qPCR reactions were as follows: $3 \mathrm{~min}$ at $94^{\circ} \mathrm{C}$ followed by $40 \mathrm{~s}$ at $94^{\circ} \mathrm{C}, 40 \mathrm{~s}$ at $60^{\circ} \mathrm{C}$, and $25 \mathrm{~s}$ at $72^{\circ} \mathrm{C}$ for 40 cycles. The expression data were normalized to $G A P D H$ as a housekeeping gene.

\section{Protein isolation, immunoprecipitation (IP) and Western blot analysis}

Protein lysates from cells were extracted in ice-cold lysis buffer consisting of 1\% NP-40, 1 mM DTT, protease inhibitors (Roche, Indianapolis, USA) and phosphatase inhibitor I and II cocktails (Sigma-Aldrich, St. Louis, MO, USA) in PBS. For Western blot analysis, total protein $(50 \mu \mathrm{g})$ was subjected to SDS-PAGE followed by immunoblotting. For IP, precleared lysates (500 
$\mu \mathrm{g}$ ) were rocked with $2 \mu \mathrm{g}$ of anti-FGFR4 polyclonal antibody (C-16; Santa Cruz Biotechnology, CA, USA) for $2 \mathrm{~h}$ at $4^{\circ} \mathrm{C}$. The immunocomplexes were precipitated with protein A sepharose (GE Healthcare Bio-Sciences AB, Uppsala, Sweden) and washed three times with lysis buffer prior to SDS-PAGE and immunoblotting analyses. Monoclonal antibodies against FGFR4 and $\beta$-actin were purchased from Santa Cruz Biotechnology (CA, USA). Primary antibodies against AKT, p-AKT (Ser473), p-AKT (Thr308), ERK1/2, p-ERK1/2, STAT3, p-STAT3 (Tyr705), PLC $\gamma$, p-PLC $\gamma$ (Tyr783) and PARP were obtained from Cell Signaling Technology (Danvers, MA, USA). Monoclonal antibody against phosphotyrosine (4G10) was purchased from Millipore Corporation (Bedford, MA, USA).

\section{Lentiviral production and transduction}

Lentiviral non-targeting shRNA (NS) and shRNA constructs targeting FGFR4 were purchased from SigmaAldrich (St. Louis, MO, USA). The shRNAs target sequences are presented in Supplementary Table S3. Lentiviral particles were generated by co-transfection of respective shRNA constructs with lentiviral packaging plasmids, psPAX2 (Addgene plasmid \#1 2260) and envelope plasmids, pMD2.G (Addgene plasmid \# 12259) into HEK$293 \mathrm{~T}$ cells, as described previously [76-78].

\section{Transfection}

Cells were seeded overnight in 96-well plates at a density of $5.0 \times 10^{3}$ cells/well prior to transfection with either of two pools of siRNAs - ON-TARGETplus Nontargeting Control Pool siRNAs and ON-TARGETplus FGF19 siRNAs (Thermo Scientific Dharmacon, Lafayette, CO, USA) using X-tremeGENE siRNA Transfection Reagent (Roche Diagnostics, IN, USA).

\section{Detection of apoptosis by annexin $\mathrm{V}$ flow cytometry}

Apoptosis was quantified using a PE Annexin V Apoptosis Detection Kit (BD Biosciences, USA) according to the manufacturer's instructions. The cells were analyzed using a FACSCalibur flow cytometer and the CellQuest Pro software (version 5.1.1; BD Biosciences, USA).

\section{FGF19 enzyme-linked immunosorbent assay (ELISA)}

Cells were seeded in 6-well plates at a density of $5 \times 10^{5}$ cells/well and supernatants were collected after $72 \mathrm{~h}$. The level of FGF19 was determined using FGF19 Quantikine ELISA kit (R\&D Systems, Mineapolis, USA) according to the manufacturer's protocol and analyzed by Tecan infinite F200 microplate reader (Männedorf,
Switzerland) at an absorbance wavelength of $450 \mathrm{~nm}$ and a correction wavelength of $540 \mathrm{~nm}$ or $570 \mathrm{~nm}$.

\section{Tissue microarrays}

Formalin-fixed, paraffin-embedded breast cancer tissue microarray (Pantomics, Richmond, CA) containing 287 nonoverlapping tissue samples were deparaffinized and rehydrated. Heat-induced epitope retrieval (HIER) method was performed to retrieve all the antigenic determinants. Primary antibodies against FGFR4 (Clone C-16) and FGF19 (MAB969) were purchased from Santa Cruz Biotechnology (CA, USA) and R\&D Systems (Mineapolis, USA), respectively. Antibodies against phospho-AKT-S473 (Clone 14-5), p53 (Clone DO-7), EGFR (clone E30), CK5/6 (clone D5/16 B4), and Ki-67 (clone MIB-1) were supplied by Dako Corporation (Carpinteria, CA, USA). Positivity was defined as the presence of $1 \%$ or more positively stained tumor cells as described previously [79-82].

\section{Statistical analysis}

The data were analyzed using SPSS version 17.0 (SPSS, INC, Chicago, IL). The chi-square test was used to evaluate any potential association between the FGFR4/FGF19 co-expression and the clinicopathologic parameters. A $P$-value $<0.05$ was considered statistically significant.

\section{CONFLICTS OF INTEREST}

The authors report no conflicts of interest pertaining to this study.

\section{GRANT SUPPORT}

This work was supported by research grants from the Malaysia Ministry of Education Fundamental Research Grant Scheme (FRGS/2/2013/SKK01/IMU/02/3) and by the International Medical University Cancer Research Fellowship Program.

\section{REFERENCES}

1. Sorlie T, Perou CM, Tibshirani R, Aas T, Geisler S, Johnsen H, Hastie T, Eisen MB, van de Rijn M, Jeffrey SS, Thorsen T, Quist H, Matese JC, et al. Gene expression patterns of breast carcinomas distinguish tumor subclasses with clinical implications. Proc Natl Acad Sci U S A. 2001; 98:10869-10874.

2. Sorlie T, Tibshirani R, Parker J, Hastie T, Marron JS, Nobel A, Deng S, Johnsen H, Pesich R, Geisler S, Demeter J, Perou CM, Lonning PE, et al. Repeated observation of breast tumor subtypes in independent gene expression data sets. Proc Natl Acad Sci U S A. 2003; 100:8418-8423. 
3. Lim LY, Vidnovic N, Ellisen LW, Leong CO. Mutant p53 mediates survival of breast cancer cells. Br J Cancer. 2009; 101:1606-1612.

4. Leong CO, Vidnovic N, DeYoung MP, Sgroi D, Ellisen LW. The p63/p73 network mediates chemosensitivity to cisplatin in a biologically defined subset of primary breast cancers. J Clin Invest. 2007; 117:1370-1380.

5. Hallett RM, Cockburn JG, Li B, Dvorkin-Gheva A, Hassell JA, Bane A. Identification and evaluation of network modules for the prognosis of basal-like breast cancer. Oncotarget. 2015; 6:17713-17724. doi: 10.18632/ oncotarget.4034.

6. Marotta LL, Polyak K. Unraveling the complexity of basal-like breast cancer. Oncotarget. 2011; 2:588-589. doi: 10.18632/oncotarget.314.

7. Rakha EA, Reis-Filho JS, Ellis IO. Basal-like breast cancer: a critical review. J Clin Oncol. 2008; 26:2568-2581.

8. Carey LA, Dees EC, Sawyer L, Gatti L, Moore DT, Collichio F, Ollila DW, Sartor CI, Graham ML, Perou CM. The triple negative paradox: primary tumor chemosensitivity of breast cancer subtypes. Clin Cancer Res. 2007; 13: 2329-2334.

9. Rouzier R, Perou CM, Symmans WF, Ibrahim N, Cristofanilli M, Anderson K, Hess KR, Stec J, Ayers M, Wagner P, Morandi P, Fan C, Rabiul I, et al. Breast cancer molecular subtypes respond differently to preoperative chemotherapy. Clin Cancer Res. 2005; 11:5678-5685.

10. Comprehensive molecular portraits of human breast tumours. Nature. 2012; 490:61-70.

11. Tiong KH, Mah LY, Leong C-O. Functional roles of fibroblast growth factor receptors (FGFRs) signaling in human cancers. Apoptosis. 2013; 18:1447-1468.

12. Touat M, Ileana E, Postel-Vinay S, Andre F, Soria JC. Targeting FGFR Signaling in Cancer. Clin Cancer Res. 2015; 21:2684-2694.

13. Turner N, Grose R. Fibroblast growth factor signalling: from development to cancer. Nat Rev Cancer. 2010; 10:116-129.

14. Li Y, Mangasarian K, Mansukhani A, Basilico C. Activation of FGF receptors by mutations in the transmembrane domain. Oncogene. 1997; 14:1397-1406.

15. Knuchel S, Anderle P, Werfelli P, Diamantis E, Ruegg C. Fibroblast surface-associated FGF-2 promotes contactdependent colorectal cancer cell migration and invasion through FGFR-SRC signaling and integrin alphavbeta5mediated adhesion. Oncotarget. 2015; 6:14300-14317. doi: 10.18632/oncotarget.3883.

16. Zhao H, Lv F, Liang G, Huang X, Wu G, Zhang W, Yu L, Shi L, Teng Y. FGF19 promotes epithelial-mesenchymal transition in hepatocellular carcinoma cells by modulating the GSK3beta/beta- catenin signaling cascade via FGFR4 activation. Oncotarget. 2016; 7:13575-86. doi: 10.18632/ oncotarget.6185.

17. Greenman C, Stephens P, Smith R, Dalgliesh GL, Hunter C, Bignell G, Davies H, Teague J, Butler A, Stevens C, Edkins S, O'Meara S, Vastrik I, et al. Patterns of somatic mutation in human cancer genomes. Nature. 2007; 446:153-158.
18. Wang J, Mikse O, Liao RG, Li Y, Tan L, Janne PA, Gray NS, Wong KK, Hammerman PS. Ligand-associated ERBB2/3 activation confers acquired resistance to FGFR inhibition in FGFR3-dependent cancer cells. Oncogene. 2015; 34:2167-2177.

19. Kunstlinger H, Fassunke J, Schildhaus HU, Brors B, Heydt C, Ihle MA, Mechtersheimer G, Wardelmann E, Buttner R, Merkelbach-Bruse S. FGFR2 is overexpressed in myxoid liposarcoma and inhibition of FGFR signaling impairs tumor growth in vitro. Oncotarget. 2015; 6:2021520230. doi: 10.18632/oncotarget.4046.

20. Qian X, Anzovino A, Kim S, Suyama K, Yao J, Hulit J, Agiostratidou G, Chandiramani N, McDaid HM, Nagi C, Cohen HW, Phillips GR, Norton L, Hazan RB. N-cadherin/ FGFR promotes metastasis through epithelial-to-mesenchymal transition and stem/progenitor cell-like properties. Oncogene. 2014; 33:3411-3421.

21. Kim B, Wang S, Lee JM, Jeong Y, Ahn T, Son DS, Park HW, Yoo HS, Song YJ, Lee E, Oh YM, Lee SB, Choi J, et al. Synthetic lethal screening reveals FGFR as one of the combinatorial targets to overcome resistance to Met-targeted therapy. Oncogene. 2015; 34:1083-1093.

22. Pollock PM, Gartside MG, Dejeza LC, Powell MA, Mallon MA, Davies H, Mohammadi M, Futreal PA, Stratton MR, Trent JM, Goodfellow PJ. Frequent activating FGFR2 mutations in endometrial carcinomas parallel germline mutations associated with craniosynostosis and skeletal dysplasia syndromes. Oncogene. 2007; 26:7158-7162.

23. Strebhardt K. Multifaceted polo-like kinases: drug targets and antitargets for cancer therapy. Nat Rev Drug Discov. 2010; 9:643-660.

24. Strebhardt K, Ullrich A. Targeting polo-like kinase 1 for cancer therapy. Nat Rev Cancer. 2006; 6:321-330.

25. Shackelford DB, Shaw RJ. The LKB1-AMPK pathway: metabolism and growth control in tumour suppression. Nat Rev Cancer. 2009; 9:563-575.

26. Yokoi A, Kotake Y, Takahashi K, Kadowaki T, Matsumoto Y, Minoshima Y, Sugi NH, Sagane K, Hamaguchi M, Iwata M. Biological validation that SF3b is a target of the antitumor macrolide pladienolide. FEBS Journal. 2011; 278:4870-4880.

27. Marsh M, McMahon HT. The structural era of endocytosis. Science. 1999; 285:215-220.

28. Zhang S, Chung WC, Wu G, Egan SE, Miele L, Xu K. Manic fringe promotes a claudin-low breast cancer phenotype through notch-mediated PIK3CG induction. Cancer Res. 2015; 75:1936-1943.

29. Chen S, Li F, Chai H, Tao X, Wang H, Ji A. miR-502 inhibits cell proliferation and tumor growth in hepatocellular carcinoma through suppressing phosphoinositide 3-kinase catalytic subunit gamma. Biochem Biophys Res Commun. 2015; 464:500-505.

30. Xie Y, Abel PW, Kirui JK, Deng C, Sharma P, Wolff DW, Toews ML, Tu Y. Identification of upregulated phosphoinositide 3-kinase gamma as a target to suppress breast cancer cell migration and invasion. Biochem Pharmacol. 2013; 85:1454-1462. 
31. Kunii K, Davis L, Gorenstein J, Hatch H, Yashiro M, Di Bacco A, Elbi C, Lutterbach B. FGFR2-amplified gastric cancer cell lines require FGFR2 and Erbb3 signaling for growth and survival. Cancer Res. 2008; 68:2340-2348.

32. Baselga J, Swain SM. Novel anticancer targets: revisiting ERBB2 and discovering ERBB3. Nat Rev Cancer. 2009; 9:463-475.

33. Schoeberl B, Pace EA, Fitzgerald JB, Harms BD, $\mathrm{Xu}$ L, Nie L, Linggi B, Kalra A, Paragas V, Bukhalid R, Grantcharova V, Kohli N, West KA, et al. Therapeutically targeting ErbB3: a key node in ligand-induced activation of the ErbB receptor-PI3K axis. Sci Signal. 2009; 2:ra31.

34. Smirnova T, Zhou ZN, Flinn RJ, Wyckoff J, Boimel PJ, Pozzuto M, Coniglio SJ, Backer JM, Bresnick AR, Condeelis JS, Hynes NE, Segall JE. Phosphoinositide 3-kinase signaling is critical for ErbB3-driven breast cancer cell motility and metastasis. Oncogene. 2012; 31:706-715.

35. Mullard A. Built-to-buy start-ups begin to bloom. Nat Rev Drug Discov. 2014; 13:161-162.

36. Sabat R, Ouyang W, Wolk K. Therapeutic opportunities of the IL-22-IL-22R1 system. Nat Rev Drug Discov. 2014; 13:21-38.

37. Fearon AE, Gould CR, Grose RP. FGFR signalling in women's cancers. Int J Biochem Cell Biol. 2013; 45:2832-2842.

38. Kennedy SG, Wagner AJ, Conzen SD, Jordan J, Bellacosa A, Tsichlis PN, Hay N. The PI 3-kinase/Akt signaling pathway delivers an anti-apoptotic signal. Genes Dev. 1997; 11:701-713.

39. Franke TF, Kaplan DR, Cantley LC. PI3K: downstream AKTion blocks apoptosis. Cell. 1997; 88:435-437.

40. Zhang $\mathrm{X}$, Ibrahimi OA, Olsen SK, Umemori H, Mohammadi M, Ornitz DM. Receptor specificity of the fibroblast growth factor family. The complete mammalian FGF family. J Biol Chem. 2006; 281:15694-15700.

41. Desnoyers LR, Pai R, Ferrando RE, Hotzel K, Le T, Ross J, Carano R, D’Souza A, Qing J, Mohtashemi I, Ashkenazi A, French DM. Targeting FGF19 inhibits tumor growth in colon cancer xenograft and FGF19 transgenic hepatocellular carcinoma models. Oncogene. 2008; 27:85-97.

42. Nicholes K, Guillet S, Tomlinson E, Hillan K, Wright B, Frantz GD, Pham TA, Dillard-Telm L, Tsai SP, Stephan JP, Stinson J, Stewart T, French DM. A mouse model of hepatocellular carcinoma: ectopic expression of fibroblast growth factor 19 in skeletal muscle of transgenic mice. Am J Pathol. 2002; 160:2295-2307.

43. Pai R, Dunlap D, Qing J, Mohtashemi I, Hotzel K, French DM. Inhibition of fibroblast growth factor 19 reduces tumor growth by modulating beta-catenin signaling. Cancer Res. 2008; 68:5086-5095.

44. Drafahl KA, McAndrew CW, Meyer AN, Haas M, Donoghue DJ. The receptor tyrosine kinase FGFR4 negatively regulates NF-kappaB signaling. PLoS One. 2010; 5:e14412.

45. Hart KC, Robertson SC, Kanemitsu MY, Meyer AN, Tynan JA, Donoghue DJ. Transformation and Stat activation by derivatives of FGFR1, FGFR3, and FGFR4. Oncogene. 2000; 19:3309-3320.
46. Wang H, Venkatesh M, Li H, Goetz R, Mukherjee S, Biswas A, Zhu L, Kaubisch A, Wang L, Pullman J, Whitney K, Kuro-o M, Roig AI, et al. Pregnane X receptor activation induces FGF19-dependent tumor aggressiveness in humans and mice. J Clin Invest. 2011; 121:3220-3232.

47. Roidl A, Berger HJ, Kumar S, Bange J, Knyazev P, Ullrich A. Resistance to chemotherapy is associated with fibroblast growth factor receptor 4 up-regulation. Clin Cancer Res. 2009; 15:2058-2066.

48. Degirolamo C, Sabba C, Moschetta A. Therapeutic potential of the endocrine fibroblast growth factors FGF19, FGF21 and FGF23. Nat Rev Drug Discov. 2016; 15:51-69.

49. Tiong KH, Mah LY, Leong CO. Functional roles of fibroblast growth factor receptors (FGFRs) signaling in human cancers. Apoptosis. 2013; 18:1447-1468.

50. Jaakkola S, Salmikangas P, Nylund S, Partanen J, Armstrong E, Pyrhonen S, Lehtovirta P, Nevanlinna H. Amplification of fgfr4 gene in human breast and gynecological cancers. Int J Cancer. 1993; 54:378-382.

51. Penault-Llorca F, Bertucci F, Adelaide J, Parc P, Coulier F, Jacquemier J, Birnbaum D and deLapeyriere O. Expression of FGF, FGF receptor genes in human breast cancer. Int $\mathbf{J}$ Cancer. 1995; 61:170-176.

52. Dallol A, Buhmeida A, Merdad A, Al-Maghrabi J, Gari MA, Abu-Elmagd MM, Elaimi A, Assidi M, Chaudhary AG, Abuzenadah AM, Nedjadi T, Ermiah E, Alkhayyat SS, et al. Frequent methylation of the KLOTHO gene and overexpression of the FGFR4 receptor in invasive ductal carcinoma of the breast. Tumour Biol. 2015; 36:9677-9683.

53. Roidl A, Foo P, Wong W, Mann C, Bechtold S, Berger HJ, Streit S, Ruhe JE, Hart S, Ullrich A, Ho HK. The FGFR4 Y367C mutant is a dominant oncogene in MDA-MB453 breast cancer cells. Oncogene. 2010; 29:1543-1552.

54. Helsten T, Elkin S, Arthur E, Tomson BN, Carter J, Kurzrock R. The FGFR Landscape in Cancer: Analysis of 4,853 Tumors by Next-Generation Sequencing. Clin Cancer Res. 2016; 22:259-267.

55. Abecasis GR, Auton A, Brooks LD, DePristo MA, Durbin RM, Handsaker RE, Kang HM, Marth GT, McVean GA. An integrated map of genetic variation from 1,092 human genomes. Nature. 2012; 491:56-65.

56. Spinola M, Leoni VP, Tanuma J, Pettinicchio A, Frattini M, Signoroni S, Agresti R, Giovanazzi R, Pilotti S, Bertario L, Ravagnani F, Dragani TA. FGFR4 Gly388Arg polymorphism and prognosis of breast and colorectal cancer. Oncol Rep. 2005; 14:415-419.

57. Spinola M, Leoni V, Pignatiello C, Conti B, Ravagnani F, Pastorino U, Dragani TA. Functional FGFR4 Gly388Arg polymorphism predicts prognosis in lung adenocarcinoma patients. J Clin Oncol. 2005; 23:7307-7311.

58. Bange J, Prechtl D, Cheburkin Y, Specht K, Harbeck N, Schmitt M, Knyazeva T, Muller S, Gartner S, Sures I, Wang H, Imyanitov E, Haring HU, et al. Cancer progression and tumor cell motility are associated with the FGFR4 Arg allele. Cancer Res. 2002; 62:840-847. 
59. Thussbas C, Nahrig J, Streit S, Bange J, Kriner M, Kates R, Ulm K, Kiechle M, Hoefler H, Ullrich A, Harbeck N. FGFR4 Arg388 allele is associated with resistance to adjuvant therapy in primary breast cancer. J Clin Oncol. 2006; 24:3747-3755.

60. Seitzer N, Mayr T, Streit S, Ullrich A. A single nucleotide change in the mouse genome accelerates breast cancer progression. Cancer Res. 2010; 70:802-812.

61. Streit S, Bange J, Fichtner A, Ihrler S, Issing W, Ullrich A. Involvement of the FGFR4 Arg388 allele in head and neck squamous cell carcinoma. Int J Cancer. 2004; 111:213-217.

62. Hynes NE, Dey JH. Potential for targeting the fibroblast growth factor receptors in breast cancer. Cancer Res. 2010; 70:5199-5202.

63. Altomare DA, Testa JR. Perturbations of the AKT signaling pathway in human cancer. Oncogene. 2005; 24:7455-7464.

64. Dey JH, Bianchi F, Voshol J, Bonenfant D, Oakeley EJ, Hynes NE. Targeting fibroblast growth factor receptors blocks PI3K/AKT signaling, induces apoptosis, and impairs mammary tumor outgrowth and metastasis. Cancer Res. 2010; 70:4151-4162.

65. Lin BC, Desnoyers LR. FGF19 and cancer. Adv Exp Med Biol. 2012; 728:183-194.

66. Bai YP, Shang K, Chen H, Ding F, Wang Z, Liang C, Xu Y, Sun MH, Li YY. FGF-1/-3/FGFR4 signaling in cancerassociated fibroblasts promotes tumor progression in colon cancer through Erk and MMP-7. Cancer Sci. 2015; 106:1278-1287.

67. Turkington RC, Longley DB, Allen WL, Stevenson L, McLaughlin K, Dunne PD, Blayney JK, Salto-Tellez M, Van Schaeybroeck S, Johnston PG. Fibroblast growth factor receptor 4 (FGFR4): a targetable regulator of drug resistance in colorectal cancer. Cell Death Dis. 2014; 5:e1046.

68. Ye Y, Jiang D, Li J, Wang M, Han C, Zhang X, Zhao C, Wen J, Kan Q. Silencing of FGFR4 could influence the biological features of gastric cancer cells and its therapeutic value in gastric cancer. Tumour Biol. 2015.

69. Ye YW, Hu S, Shi YQ, Zhang XF, Zhou Y, Zhao CL, Wang GJ, Wen JG, Zong H. Combination of the FGFR4 inhibitor PD173074 and 5-fluorouracil reduces proliferation and promotes apoptosis in gastric cancer. Oncol Rep. 2013; 30:2777-2784.

70. Li J, Ye Y, Wang M, Lu L, Han C, Zhou Y, Zhang J, Yu Z, Zhang X, Zhao C, Wen J, Kan Q. The over-expression of FGFR4 could influence the features of gastric cancer cells and inhibit the efficacy of PD173074 and 5-fluorouracil towards gastric cancer. Tumour Biol. 2015.

71. Ramaswamy S, Nakamura N, Vazquez F, Batt DB, Perera S, Roberts TM, Sellers WR. Regulation of G1 progression by the PTEN tumor suppressor protein is linked to inhibition of the phosphatidylinositol 3-kinase/Akt pathway. Proc Natl Acad Sci U S A. 1999; 96:2110-2115.

72. Hillion J, Dhara S, Sumter TF, Mukherjee M, Di Cello F, Belton A, Turkson J, Jaganathan S, Cheng L, Ye Z, Jove R,
Aplan P, Lin YW, et al. The high-mobility group A1a/signal transducer and activator of transcription-3 axis: an achilles heel for hematopoietic malignancies? Cancer Res. 2008; 68:10121-10127.

73. Konig R, Chiang CY, Tu BP, Yan SF, DeJesus PD, Romero A, Bergauer T, Orth A, Krueger U, Zhou Y, Chanda SK. A probability-based approach for the analysis of large-scale RNAi screens. Nat Methods. 2007; 4:847-849.

74. Tan BS, Tiong KH, Choo HL, Chung FF, Hii LW, Tan SH, Yap IK, Pani S, Khor NT, Wong SF, Rosli R, Cheong SK, Leong CO. Mutant p53-R273H mediates cancer cell survival and anoikis resistance through AKT-dependent suppression of BCL2-modifying factor (BMF). Cell Death Dis. 2015; 6:e1826.

75. Low SY, Tan BS, Choo HL, Tiong KH, Khoo AS, Leong CO. Suppression of BCL-2 synergizes cisplatin sensitivity in nasopharyngeal carcinoma cells. Cancer Lett. 2012; 314:166-175.

76. Ibrahim N, He L, Leong CO, Xing D, Karlan BY, Swisher EM, Rueda BR, Orsulic S, Ellisen LW. BRCA1associated epigenetic regulation of $\mathrm{p} 73$ mediates an effector pathway for chemosensitivity in ovarian carcinoma. Cancer Res. 2010; 70:7155-7165.

77. Rocco JW, Leong CO, Kuperwasser N, DeYoung MP, Ellisen LW. p63 mediates survival in squamous cell carcinoma by suppression of p73-dependent apoptosis. Cancer Cell. 2006; 9:45-56.

78. Tan BS, Tiong KH, Muruhadas A, Randhawa N, Choo HL, Bradshaw TD, Stevens MF, Leong CO. CYP2S1 and CYP2W1 Mediate 2-(3,4-Dimethoxyphenyl)-5Fluorobenzothiazole (GW-610, NSC 721648) Sensitivity in Breast and Colorectal Cancer Cells. Mol Cancer Ther. 2011; 10:1982-1992.

79. Livasy CA, Karaca G, Nanda R, Tretiakova MS, Olopade OI, Moore DT, Perou CM. Phenotypic evaluation of the basal-like subtype of invasive breast carcinoma. Mod Pathol. 2006; 19:264-271.

80. Nielsen TO, Hsu FD, Jensen K, Cheang M, Karaca G, $\mathrm{Hu} \mathrm{Z}$, Hernandez-Boussard T, Livasy C, Cowan D, Dressler L, Akslen LA, Ragaz J, Gown AM, et al. Immunohistochemical and clinical characterization of the basal-like subtype of invasive breast carcinoma. Clin Cancer Res. 2004; 10:5367-5374.

81. Kanapathy Pillai SK, Tay A, Nair S, Leong CO. Triplenegative breast cancer is associated with EGFR, CK5/6 and c-KIT expression in Malaysian women. BMC Clin Pathol. 2012; 12:18.

82. Silver DP, Richardson AL, Eklund AC, Wang ZC, Szallasi Z, Li Q, Juul N, Leong CO, Calogrias D, Buraimoh A, Fatima A, Gelman RS, Ryan PD, et al. Efficacy of neoadjuvant cisplatin in triple-negative breast cancer. J Clin Oncol. 2010; 28:1145-1153. 